\title{
Prodynorphin Peptide Distribution in the Forebrain of the Syrian Hamster and Rat: A Comparative Study With Antisera Against Dynorphin A, Dynorphin B, and the C-Terminus of the Prodynorphin Precursor Molecule
}

\author{
CHARLES RICHARD NEAL, JR, AND SARAH WINANS NEWMAN \\ Department of Anatomy and Cell Biology, University of Michigan Medical School, Ann Arbor, \\ Michigan 48109-0616
}

\begin{abstract}
The neuroanatomical distribution of the prodynorphin precursor molecule in the forebrain of the male Syrian hamster (Mesocricetus auratus) has been studied with a novel antiserum directed against the C-terminus of the leumorphin [dynorphin B (1-29)] peptide product. C-peptide staining in sections from colchicine-treated hamsters is compared to staining in sections from untreated animals. In addition, the pattern of C-peptide immunostaining in hamster brain is compared to that in the rat brain. Finally, the C-peptide immunolabeling patterns in hamsters and rats are compared to those obtained with antisera to dynorphin A (1-17) and dynorphin B (1-13).

Areas of heaviest prodynorphin immunoreactivity in the hamster include the hippocampal formation, lateral septum, bed nucleus of the stria terminalis, medial preoptic area, medial and central amygdaloid nuclei, ventral pallidum, substantia nigra, and numerous hypothalamic nuclei. Although this $\mathrm{C}$ peptide staining pattern is similar to dynorphin staining reported previously in the rat, several species differences are apparent. Whereas moderate dentate gyrus granule cell staining and no CA4 cell staining have been reported in the rat hippocampal formation, intense immunostaining in the dentate gyrus and CA4 cell labeling are observed in the hamster. In addition, the medial preoptic area, bed nucleus of the stria terminalis, and medial nucleus of the amygdala stain lightly for prodynorphin-containing fibers and cells in the rat, compared to heavy cell and fiber staining in the hamster in all three of these regions.

In the rat there is no differential staining between tissues processed with the C-peptide, dynorphin A, and dynorphin B antisera, but numerous areas of the hamster brain show striking differences. In most hamster brain areas containing prodynorphin peptides, the C-peptide antiserum immunolabels more cells and fibers than the dynorphin $\mathrm{B}$ antiserum, which in turn labels more cells and fibers than dynorphin A antiserum. However, exceptions to this hierarchy of staining intensity are found in the lateral hypothalamus, substantia nigra, arcuate nucleus, and habenula. The differences in staining patterns between rat and hamster are greatest when C-peptide antiserum is used; apparent species differences are present, though less pronounced, in dynorphin B- and dynorphin A-immunostained material.
\end{abstract}

Key words: neuropeptides, dynorphin, limbic system, opioids, immunohistochemistry 
As a result of a series of behavioral and neuroanatomical studies, a central nervous system pathway has been described through which vomeronasal and olfactory sensory systems control the copulatory behavior of the male Syrian hamster (Mesocricetus auratus; Winans et al., '82). Central structures of this facilitatory pathway include the medial nucleus of the amygdala (Lehman et al., '80; Lehman and Winans, '82) and its projections to the medial division of the bed nucleus of the stria terminalis and the medial preoptic area (Kevetter and Winans, '81; Lehman et al., '83; Lehman and Winans, '83; Powers et al., '87; Maragos et al., '89).

Although lesion and tract-tracing studies have identified these three structures as critical areas for maintenance of male hamster sexual behavior, the neurotransmitters or neuromodulators specific to this circuitry have not been defined. To address this issue we performed immunohistochemical studies on hamster brain tissue with antisera against several peptides known to influence mating behavior. Surprisingly, numerous neurons were immunolabeled in the amygdala, the bed nucleus of the stria terminalis, and the medial preoptic area (Neal et al., '89) both with antisera against substance $P$, which has been shown to facilitate mating behavior (Dornan and Malsbury, '87; Dornan et al., '87), and with antisera against dynorphin, one of the opioid peptides, which as a class are known to reduce this behavior (Pfaus and Gorzalka, '87).

Behavioral experiments have provided strong evidence for the inhibitory role of opiates and endogenous opioid peptides in mating behavior of both male Syrian hamsters (Murphy et al., '79; Murphy, '81; Wu and Noble, '86) and male rats (Meyerson and Terenius, '77; Tokunaga et al., '77; Pellegrini-Quarantotti et al., '78; Gessa and Paglietta, '79; Mumford and Kumar, '79; Myers and Baum, '79, '80; McIntosh et al., '80; Meyerson, '82; Imura et al., '85; Lieblich et al., '85; Allen et al., ' 85 ). In the Syrian hamster, methadone has been shown to cause a naltrexone-reversible doserelated decline in sexual performance and motivation (Murphy, '81). In the same species, levels of beta-endorphin, a proopiomelanocortin peptide product, are elevated during the postejaculatory interval, a period when the male typically ignores the receptive female (Murphy et al., '79). Further, the opiate antagonists naloxone and naltrexone, given alone, have been shown to facilitate male hamster copulatory behavior ( $\mathrm{Wu}$ and Noble, '86). As hypothesized by Myers and Baum ('80), the activation of opiate receptors in the male rodent brain during normal copulation may be necessary to slow down the pattern of copulatory behavior to a level optimal for female impregnation. Data from both rats and hamsters indicate that if ejaculation occurs too quickly and is preceded by too few intromissions, impregnation is inhibited (Adler, '69; Lanier et al., '75). The modulation of the male's copulatory behavior by opiate receptor activation may in this way contribute to reproductive success of the species.

More recent evidence, however, indicates that one of the endogenous opioids, the prodynorphin product dynorphin $B$ [1-29], also known as leumorphin, may facilitate female sexual behavior (Sakuma and Akaishi, '87). Other prodynorphin products have been reported to facilitate male sexual behavior as well (Band and Hull, '88; Mitchell and Stewart, '88). These leumorphin and dynorphin effects are in contrast to the inhibitory actions of other opioid family peptides on sexual behavior.

Our preliminary data demonstrated prodynorphin staining patterns in the medial nucleus of the amygdala, medial bed nucleus of the stria terminalis, and medial preoptic area in the hamster but not the rat. Such species differences in prodynorphin peptide distribution have not been described previously, although they may not be surprising in light of the differential distribution of opiate receptors reported in various species (Mansour et al., '88).

Our overall objective is, therefore, to determine the specific distribution of all three families of opioid peptides in the male hamster brain. The results presented here define the neuroanatomical distribution of one of these opioid peptide families, the dynorphins, a family of endogenous opioid peptides derived from a common precursor molecule (prodynorphin; proenkephalin B), all of which contain a leucineenkephalin sequence at their $\mathrm{N}$-terminus. The immunocytochemical distribution of prodynorphin products in the central nervous system of the rat has been reported in detail (Khachaturian et al., '82; Fallon and Leslie, '86). 'This distribution has also been studied by using radioimmunoassay (Palkovits et al., '83; Zamir et al., '83). However, no comprehensive studies have been done in other animal models, and to our knowledge, the only report of dynorphin immunocytochemistry in the hamster brain has been dynorphin $\mathrm{B}$ immunolabeling in the hippocampal formation of noncolchicine-treated animals (Mclean et al., '87). We have, therefore, compared prodynorphin peptide distribution in colchicine- and noncolchicine-treated hamster material to that of simultaneously processed rat brain sections.

For these studies we have compared the immunocytochemical distribution of prodynorphin peptide products in the rat and hamster forebrain by using antisera against dynorphin A, dynorphin B, and C-peptide. The C-peptide antiserum used is a novel polyclonal antiserum directed against the C-terminus of the leumorphin fragment of the rat prodynorphin precursor molecule. Leumorphin (Dyn B [1-29]) has been sequenced in the pig (Kakidani et al., '82), cow (Yamamoto et al., '83), and human (Suda et al., ' 84 b), as well as in the rat (Civelli et al., '85). In addition, the receptor binding and physiological activities of the porcine form have been investigated (Yamamoto et al., '83; Tojo et al., '85; Imura et al., '85; Sakuma and Akaishi, '87).

The results reported here represent an analysis of C-peptide localization in the hamster forebrain with dynorphin $B$ and dynorphin A immunoreactivity patterns reported for comparison. In addition, immunohistochemical labeling of the rat forebrain with the C-peptide, dynorphin $B$, and dynorphin A antisera has been compared to the hamster.

\section{MATERIALS AND METHODS Animals}

Forty-four adult male Syrian hamsters (M. auratus; 100 $150 \mathrm{~g})$ and seven Sprague-Dawley rats (250-300 g) were used. We studied brains of colchicine-treated hamsters cut in the coronal, sagittal, and horizontal planes, as well as noncolchicine-treated brains cut coronally and sagittally. All rat brains were colchicine treated and cut in the coronal plane, and all were immunostained with procedures identical to those described below for hamster brains.

\section{Colchicine treatment, perfusion, and tissue processing}

Hamsters were anesthetized with sodium pentobarbital ( $10 \mathrm{mg} / 100 \mathrm{~g}$ body weight). Two microliters of $160 \mu \mathrm{g} / \mu \mathrm{l} \mathrm{col-}$ chicine solution were injected stereotaxically into the left 
lateral ventricle at the level of the septum $(\mathrm{ML}=+1.5$ from bregma, $\mathrm{AP}=+1.5$ from bregma and $\mathrm{DV}=-3.3$ from dura, with bregma and lambda in the same horizontal plane). Rats were anesthetized with sodium pentobarbital $(5 \mathrm{mg} / 100 \mathrm{~g}$ body weight) and $2 \mu \mathrm{l}$ of $80 \mu \mathrm{g} / \mu \mathrm{l}$ colchicine solution were injected stereotaxically into the left lateral ventricle at the level of the septum $(\mathrm{ML}=+1.0$ from bregma, $\mathrm{AP}=+1.5$ from bregma, and DV $=-3.5$ from dura, with bregma and lambda in the same horizontal plane). To compare the effects of different dosages of colchicine on immunostaining, three pairs of brains were processed in which one rat and one hamster each received 80,160 , or $320 \mu \mathrm{g}$ of colchicine.
Following a survival period of 24-72 hours, the hamsters were anesthetized with pentobarbital $(15 \mathrm{mg} / 100 \mathrm{~g}$ body weight) and perfused transcardially. All brains were washed with $100 \mathrm{ml}$ of a $0.1 \mathrm{M}$ phosphate-buffered saline solution (PBS) with $0.1 \%$ sodium nitrite (for vasodilation), followed by $150-200 \mathrm{ml}$ of fixative. The fixative was either a $4 \%$ paraformaldehyde solution in $0.1 \mathrm{M}$ sodium phosphate buffer or a $2 \%$ paraformaldehyde and $0.25 \%$ parabenzoquinone solution in $50 \mathrm{mM}$ sodium phosphate buffer. Noncolchicinetreated animals were perfused identically. Most brains were then postfixed for 1 hour (4\% paraformaldehyde brains), or for 4 hours (parabenzoquinone brains) in the perfusion fixative, followed by soaking in a solution of $20 \%$ sucrose in ac

anterior commissure

nucleus accumbens

nucleus accumbens, core

nucleus accumbens, shell

central nucleus of the amygdala

anterior continuation of the hippocampus

anterior cortical nucleus of the amygdala

anterodorsal preoptic nucleus

anterior hypothalamic area

anterior hippocampal area

agranular insular cortex

AHA

alac, ALAC

AMe

AONd

AONl

AONm

AONp

AONy

$\mathrm{Aq}$

Arc

BLa

BLp

$\mathrm{BM}$

BNST

BNSTe

BNSTI

BNSTm

CA1

CA2

CA3

CA4

cc

CG

$\mathrm{Cg}$

CP

DG

$\mathrm{DMH}$

En

Ent

f

fr

FStr

GP

$\mathrm{Hb}$

$\mathrm{HbC}$

HLNDB

ic

ICj

ICM

IG

III

IL

IPN

lot

LH

lHb

La

Lp

LPOA
作

medial nucleus of the amygdala

anterior olfactory nucleus, dorsal part

anterior olfactory nucleus, lateral part

anterior olfactory nucleus, medial part anterior olfactory nucleus, posterior part anterior olfactory nucleus, ventral part aqueduct of Sylvius (cerebral aqueduct)

arcuate nucleus of the hypothalamus anterior basolateral nucleus of the amygdala posterior basolateral nucleus of the amygdala basomedial nucleus of the amygdala bed nucleus of the stria terminalis bed nucleus of the stria terminalis, external part bed nucleus of the stria terminalis, lateral part bed nucleus of the stria terminalis, medial part Cornus Ammonus, region 1

Cornus Ammonus, region 2

Cornus Ammonus, region 3

Cornus Ammonus, region 4

corpus callosum

central gray

cingulate cortex

caudate-putamen

dentate gyrus

dorsomedial hypothalamic area

endopiriform nucleus

entorhinal cortex

entopeduncular nucleus

fornix

fasciculus retroflexus

fundus striati

globus pallidus

habenula

habenular commissure

$\mathrm{n}$. of the diagonal band of Broca, horizontal limb

internal capsule

islands of Calleja

insula Calleja magna complex

indusium griseum

third ventricle

infralimbic cortex

interpeduncular nucleus

lateral olfactory tract

lateral hypothalamic area

lateral habenula

lateral amygdaloid nucleus, anterior division

lateral amygdaloid nucleus, posterior division

lateral preoptic area
Abbreviations

\begin{tabular}{|c|c|}
\hline LSD & dorsal lateral septum \\
\hline LSI & intermediate lateral septum \\
\hline LSV & ventral lateral septum \\
\hline LV & lateral ventricle \\
\hline MePO & median preoptic nucleus \\
\hline MGN & medial geniculate nucleus \\
\hline $\mathrm{mHb}$ & medial habenula \\
\hline MI & massa intercalata \\
\hline MM & medial mammillary nucleus \\
\hline $\mathrm{MnM}$ & median mammillary nucleus \\
\hline MO & medial orbital cortex \\
\hline MPN & medial preoptic nucleus \\
\hline MPNmag & medial preoptic nucleus, magnocellular part \\
\hline MPOA & medial preoptic area \\
\hline MS & medial septum \\
\hline $\mathrm{mt}$ & mammillothalamic tract \\
\hline NAOT & nucleus of the accessory olfactory tract \\
\hline NLOT & nucleus of the lateral olfactory tract \\
\hline$o c, O C$ & optic chiasm \\
\hline ot, OT & optic tract \\
\hline OTu & olfactory tubercle \\
\hline pc & posterior commissure \\
\hline $\mathrm{Pe}$ & periventricular nucleus of the hypothalamus \\
\hline PeF & perifornical area \\
\hline PfN & parafascicular nucleus of the thalamus \\
\hline PH & posterior hypothalamic area \\
\hline PIL & posterior intralaminar nucleus of the thalamus \\
\hline PLCO & posterolateral cortical nucleus of the amygdala \\
\hline PMCo & posteromedial cortical nucleus of the amygdala \\
\hline PMD & dorsal premammillary nucleus \\
\hline PMV & ventral premammillary nucleus \\
\hline POC & primary olfactory cortex \\
\hline PPN & peripeduncular nucleus \\
\hline pr & pineal recess \\
\hline PrC & precommissural nucleus \\
\hline PSN & parastrial nucleus \\
\hline PT & parataenial nucleus of the thalamus \\
\hline PVN & paraventricular nucleus of the hypothalamus \\
\hline PVPO & preoptic periventricular nucleus \\
\hline $\mathrm{RN}$ & red nucleus \\
\hline S & subiculum \\
\hline SC & superior colliculus \\
\hline $\mathrm{SCN}$ & suprachiasmatic nucleus of the hypothalamus \\
\hline $\mathrm{sm}$ & stria medullaris \\
\hline SM & supramammillary nucleus \\
\hline SNC & substantia nigra, pars compacta \\
\hline SNR & substantia nigra, pars reticulata \\
\hline SON & supraoptic nucleus of the hypothalamus \\
\hline SOR & retrochiasmatic supraoptic nucleus of the hypothalamus \\
\hline sox & supraoptic decussation \\
\hline st & stria terminalis \\
\hline STh & subthalamic nucleus \\
\hline $\operatorname{Tr}$ & transitional area of Haug \\
\hline TT & tenia tecta \\
\hline VLNDB & nucleus of the diagonal band of Broca, vertical limb \\
\hline VMH & ventromedial nucleus of the hypothalamus \\
\hline vp & ventral amygdaloid pathway \\
\hline VP & ventral pallidum \\
\hline VTA & ventral tegmental area \\
\hline ZI & zona incerta \\
\hline
\end{tabular}




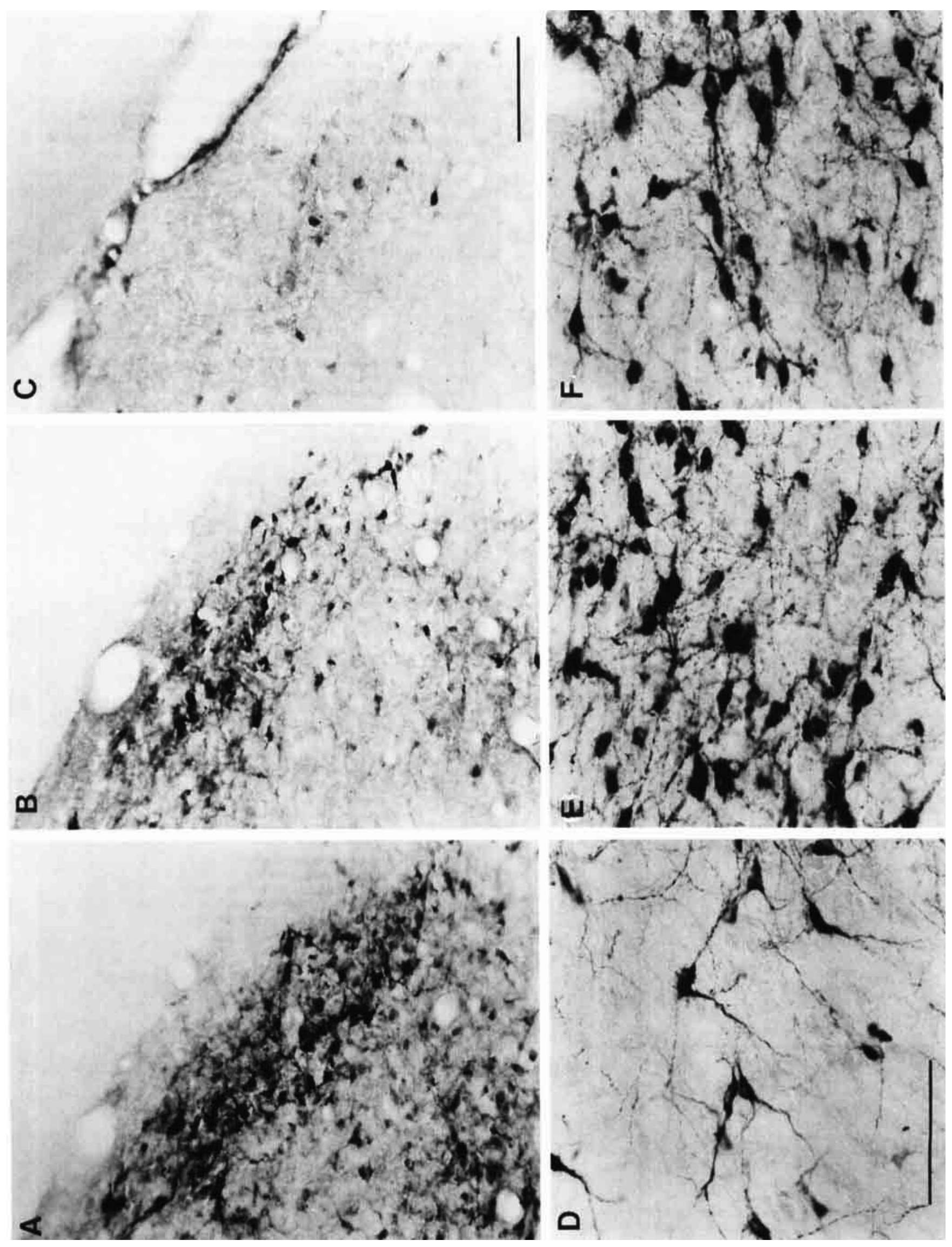



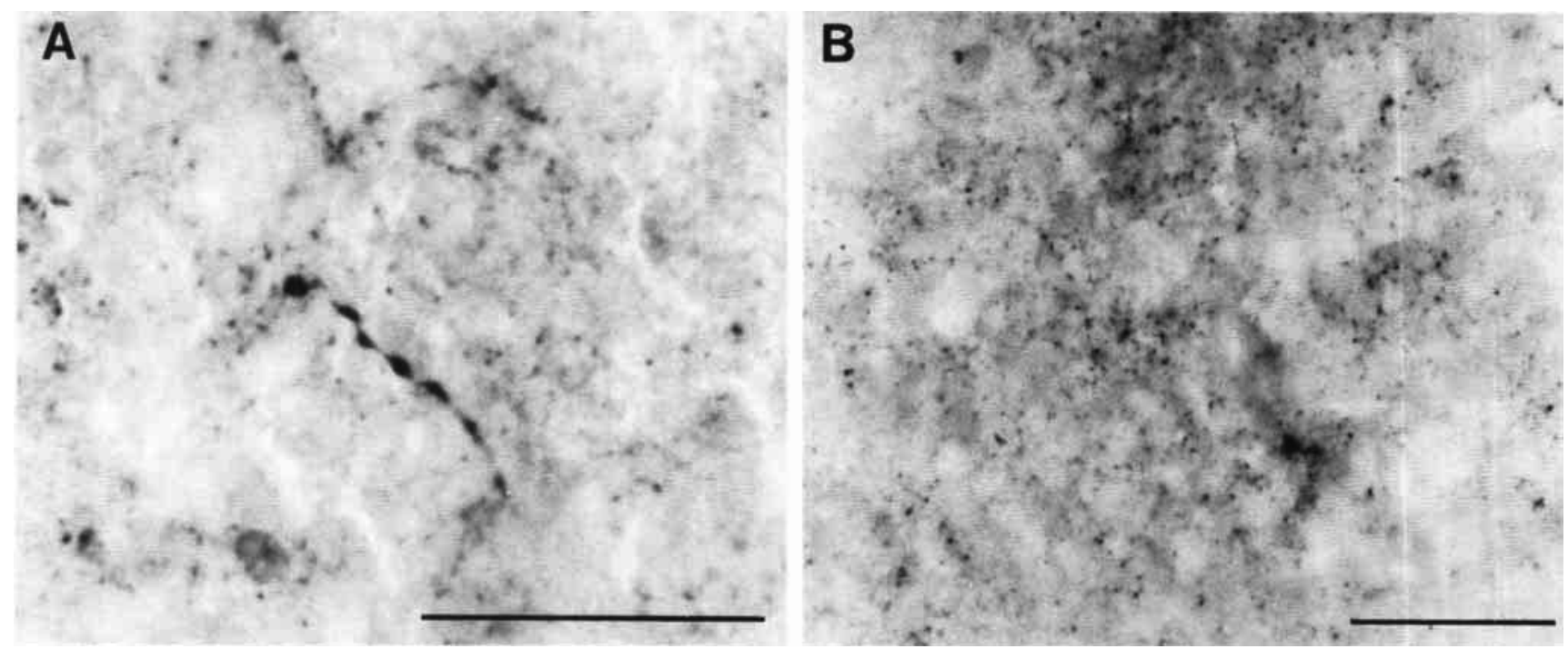

Fig. 2. Photomicrographs demonstrating characteristic differences in staining between an immunoreactive fiber amongst punctate terminals in the anterior hypothalamic area (A) and a terminal patch in the parataenial nucleus of the thalamus (B) with PAP immunohistochemistry of the C-peptide antiserum. Calibration bars equal $50 \mu \mathrm{m}$.

PBS at $4^{\circ} \mathrm{C}$ for at least 24 hours. Forty-micrometer sections were cut on a freezing microtome and stored at $4^{\circ} \mathrm{C}$ with 0.1 $\mathrm{M}$ sodium phosphate buffer and $0.01 \%$ sodium azide for preservation of tissues.

Rats used in this study survived $24-48$ hours after colchicine treatment before they were anesthetized with pentobarbital ( $15 \mathrm{mg} / 100 \mathrm{~g}$ body weight) and perfused transcardially. All brains were washed with $250 \mathrm{ml}$ of PBS with $0.1 \%$ sodium nitrite. In five animals the wash was followed by 400 $\mathrm{ml}$ of $2 \%$ paraformaldehyde and $0.25 \%$ parabenzoquinone solution in $50 \mathrm{mM}$ sodium phosphate buffer. Two rats were fixed with $400 \mathrm{ml}$ of $4 \%$ paraformaldehyde in $0.1 \mathrm{M}$ sodium phosphate buffer for comparison to paraformaldehydefixed hamster tissue. Further processing of rat brains was identical to that of the hamster brain tissue.

\section{Antisera}

The C-peptide (\#109, bleed 6) and dynorphin B [1-13] (\#94, bleed 6) antisera used in this study were generously provided by Dr. Stanley Watson, Mental Health Research Institute, University of Michigan. The dynorphin A [1-17] (AK84T) and dynorphin B [1-13] (AK113T) antisera were a

Fig. 1. Photomicrographs of similar levels of the caudal posterodorsal subdivision of the medial nucleus of the amygdala and the lateral hypothalamic area in the hamster, showing comparisons of $\mathrm{C}$-peptide immunoreactivity $(\mathbf{A}, \mathbf{D})$, dynorphin $B[1-13]$ immunoreactivity $(\mathbf{B}, \mathbf{E})$, and dynorphin A [1-17] immunoreactivity (C, F). Both dynorphin B (B) and dynorphin $A(C)$ immunolabeling are weaker than that of C-peptide (A) in the medial nucleus of the amygdala, with dynorphin $B$ immunostaining also visibly greater than that of dynorphin $\mathrm{A}$. In the lateral hypothalamus both dynorphin B immunostaining (E) and dynorphin $A$ immunostaining (F) are as heavy or heavier than that of C-peptide (D). Both calibration bars equal $100 \mu \mathrm{m}$. The bar in $\mathrm{C}$ applies to $\mathrm{A}-\mathrm{C}$ and the bar in $\mathrm{D}$ applies to $\mathrm{D}-\mathrm{F}$. generous gift of Dr. Lars Terenius, Uppsala University, Uppsala, Sweden.

\section{Immunohistochemistry}

A modification of the Sternberger peroxidase-antiperoxidase (PAP) method for free-floating sections was used on all brains (Sternberger et al., '70). Rat and hamster brain sections were incubated for 30 minutes in $1 \%$ sodium borohydride or $0.022 \mathrm{M}$ potassium-phosphate-buffered saline (KPBS), then washed $3 \times 5$ minutes in KPBS, and transferred to primary antiserum diluted to a desired concentration with $0.3 \%$ Triton-X in the KPBS for 48-60 hours. All primary antisera were used in dilutions we had determined to be optimal for staining: C-peptide (1:400-1:500), dynorphin B (1:250), and dynorphin A (1:250). After incubation in primary antiserum, sections were incubated in a goat antirabbit (GAR) solution diluted to 1:50 with the Triton$\mathrm{X}$-KPBS solution for 1 hour and then in a 1:100 dilution of rabbit peroxidase antiperoxidase complex in the Triton-XKPBS solution for 1 hour. After each incubation, the sections were washed $3 \times 5$ minutes in KPBS. Finally, they were stained for 15 minutes in a diaminobenzidine (DAB) staining solution. To prepare the DAB solution, nickle chloride $(\mathrm{NiCl})$ and $\mathrm{H}_{2} \mathrm{O}_{2}$ were mixed into $0.0125 \% \mathrm{DAB}$ in $\mathrm{KPBS}$, to yield a final concentration of $0.625 \mathrm{mM} \mathrm{NiCl}$ and $0.06 \% \mathrm{H}_{2} \mathrm{O}_{2}$. After six to ten water washes the sections were immediately mounted from $0.1 \mathrm{M}$ sodium phosphate buffer onto gelatin-coated slides, dried overnight, dehydrated, and coverslipped with Permount.

Adjacent sections were mounted and counterstained with cresyl violet to provide cytoarchitectonic information with which immunocytochemical data could be compared.

In three hamster and three rat brains, indirect immunofluorescence immunohistochemistry was used in addition to the PAP method in order to compare results. For the immu- 

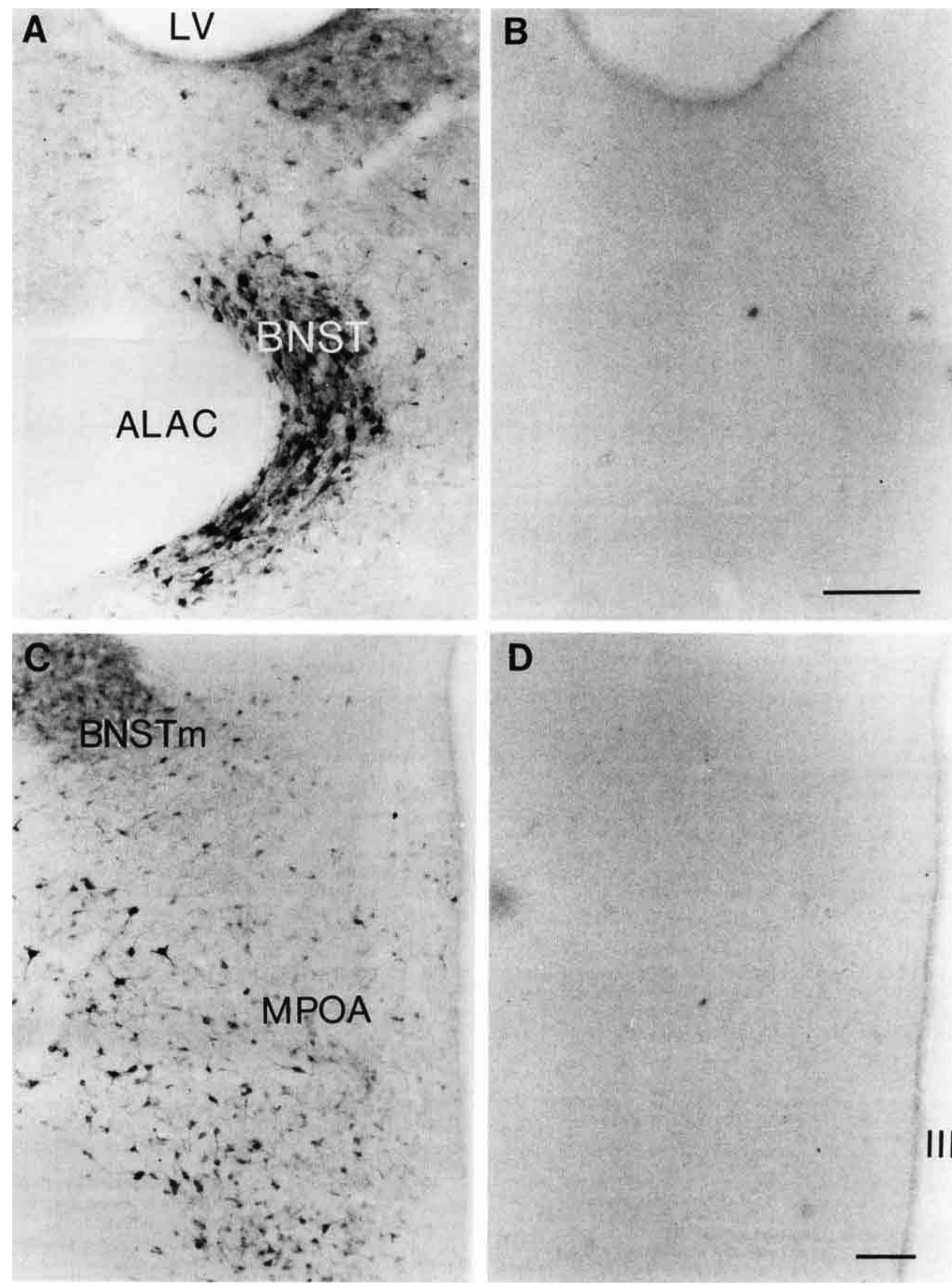

D

III 


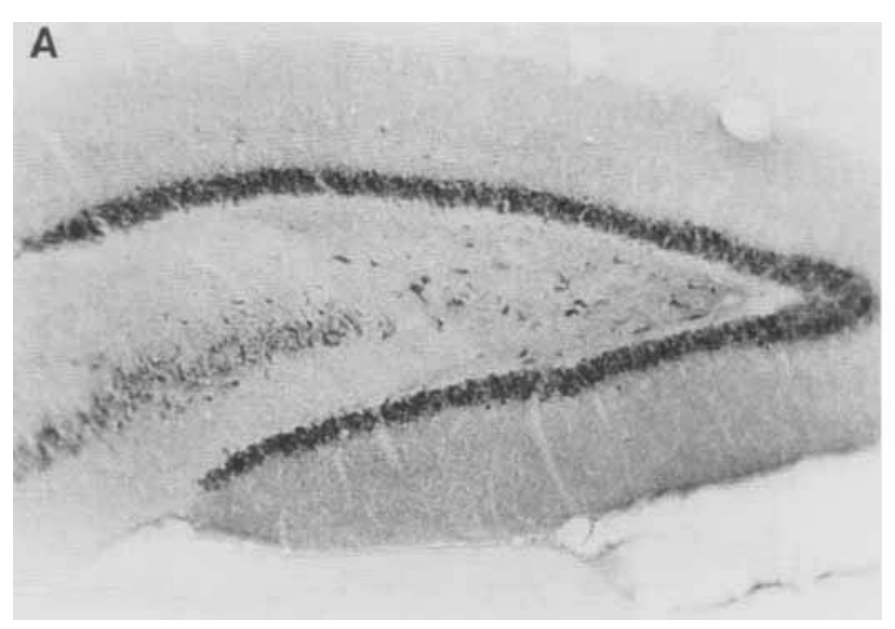

Fig. 4. Photomicrograph of C-peptide immunoreactivity in the dentate gyrus/CA4 region of the hamster hippocampal formation (A). B: Cpeptide antiserum was preabsorbed with a $5 \mu \mathrm{M}$ concentration of the C-terminus peptide against which the antiserum was made. Photomi-

nofluorescence procedure, tissue sections were incubated in primary antisera in a manner identical to that of the PAP procedure described above. After $48-60$ hours in primary antiserum, the sections were washed $3 \times 5$ minutes in KPBS and then incubated for 1 hour in a 1:40 dilution of fluorescein isothiocyanate (FITC)-labeled goat antirabbit secondary antiserum. The sections were then washed six to ten times with distilled water, mounted on gelatin-coated slides, and coverslipped with a glycerol-phosphate buffer medium containing phenylenediamine (for optimal preservation of FITC immunofluorescence; Platt and Michael, '83). These sections were analyzed with a Leitz Orthoplan fluorescence microscope under blue light excitation to induce green-blue emission from FITC.

\section{Controls}

To test the specificity of the antisera used, a series of control staining procedures were carried out. To check for primary antiserum specificity (self-blocking control), the C-peptide antiserum was preabsorbed with a $5-10 \mu \mathrm{M}$ concentration of rat C-terminus peptide (generously donated by Dr. Stanley Watson), a $50-100 \mu \mathrm{M}$ concentration of porcine C-terminus peptide (Penninsula Labs), or 50-100 $\mu \mathrm{M}$ human leumorphin peptide (Penninsula Labs) prior to tissue incubation. To check for cross-reactivity of the $\mathrm{C}$ peptide antiserum used with other opioid peptides (crossblocking control), the primary antiserum was preabsorbed with 50-100 $\mu \mathrm{M}$ dynorphin B [1-13] peptide, dynorphin A [1-17] peptide, dynorphin A [1-13] peptide, leucine-enkephalin peptide, methionine-enkephalin peptide, ACTH [1-

Fig. 3. Photomicrographs of C-peptide immunoreactivity in the rostral bed nucleus of the stria terminalis capping the anterior limb of the anterior commissure $(\mathbf{A}, \mathbf{B})$ and caudal part of the medial preoptic area $(C, D)$ in the hamster. B and D: C-peptide antiserum was preabsorbed with a $10 \mu \mathrm{M}$ concentration of the C-terminus peptide against which the antiserum was made. See text for details. Calibration bars equal 100 $\mu \mathrm{m}$.

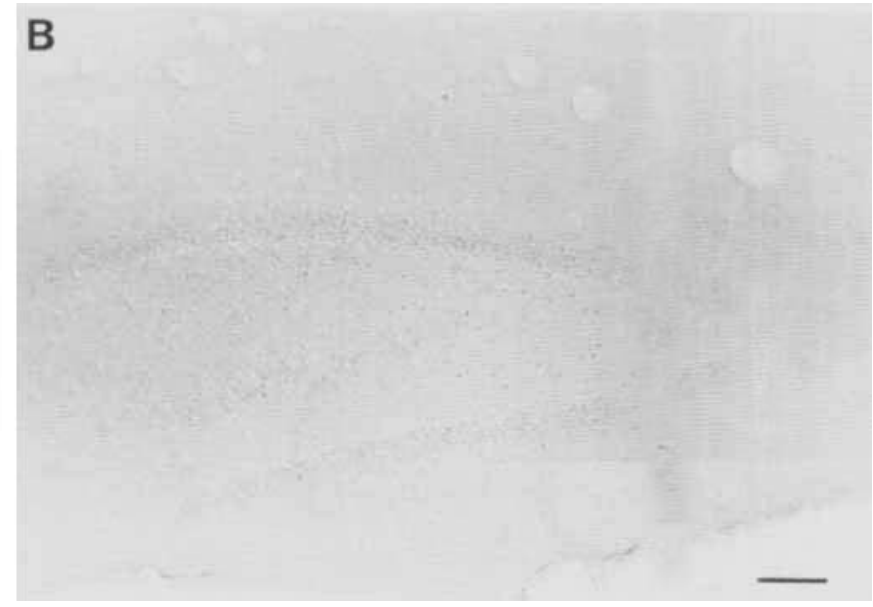

crographs were taken by using phase contrast to allow visualization of anatomical landmarks in the unstained control tissue. Calibration bar equals $100 \mu \mathrm{m}$.

$24]$ peptide, or $\beta$-endorphin peptide (Penninsula Labs) prior to tissue incubation. To check for goat antirabbit, PAP, or FITC-goat antirabbit antisera recognizing any epitopes in the hamster brain, sections were run through the PAP or immunofluorescence procedure with KPBS in place of the primary antiserum. The dynorphin A and dynorphin $B$ antisera were preabsorbed prior to immunostaining with the same dynorphin A [1-17], dynorphin A [1-13], dynorphin B [1-13], and leu-enkephalin peptides at similar concentrations as those used for the C-peptide blocking controls described above.

\section{RESULTS Comments on methods}

Colchicine surgery. Hamsters that have been treated with colchicine typically show postoperative shaking and other signs of discomfort. These symptoms were alleviated in all animals with a sedative injection of sodium pentobarbital ( $5 \mathrm{mg} / 100 \mathrm{~g}$ body weight), after which the animals awakened to be relatively calm. They were, however, unusually sensitive to handling $24-60$ hours postoperatively. We monitored all these signs for indications of successful ventricular injections. With this procedure in hamsters, the mortality rate was negligible with $320 \mu \mathrm{g}$ of colchicine. We lost no animals with lower doses of colchicine.

Rats showed little reaction to the colchicine injection post-operatively, but the mortality rate was higher than that of hamsters after $24-48$ hours with 320 or $160 \mu \mathrm{g}$ colchicine.

There was a profound difference in immunocytochemical staining between brains of colchicine- and noncolchicinetreated animals. Brains of untreated animals contained almost no labeled cell bodies, although areas of most robust staining (e.g., lateral hypothalamic area and supraoptic nucleus) did contain a few lightly stained cells. For analysis of fiber staining, however, these animals were an added source 


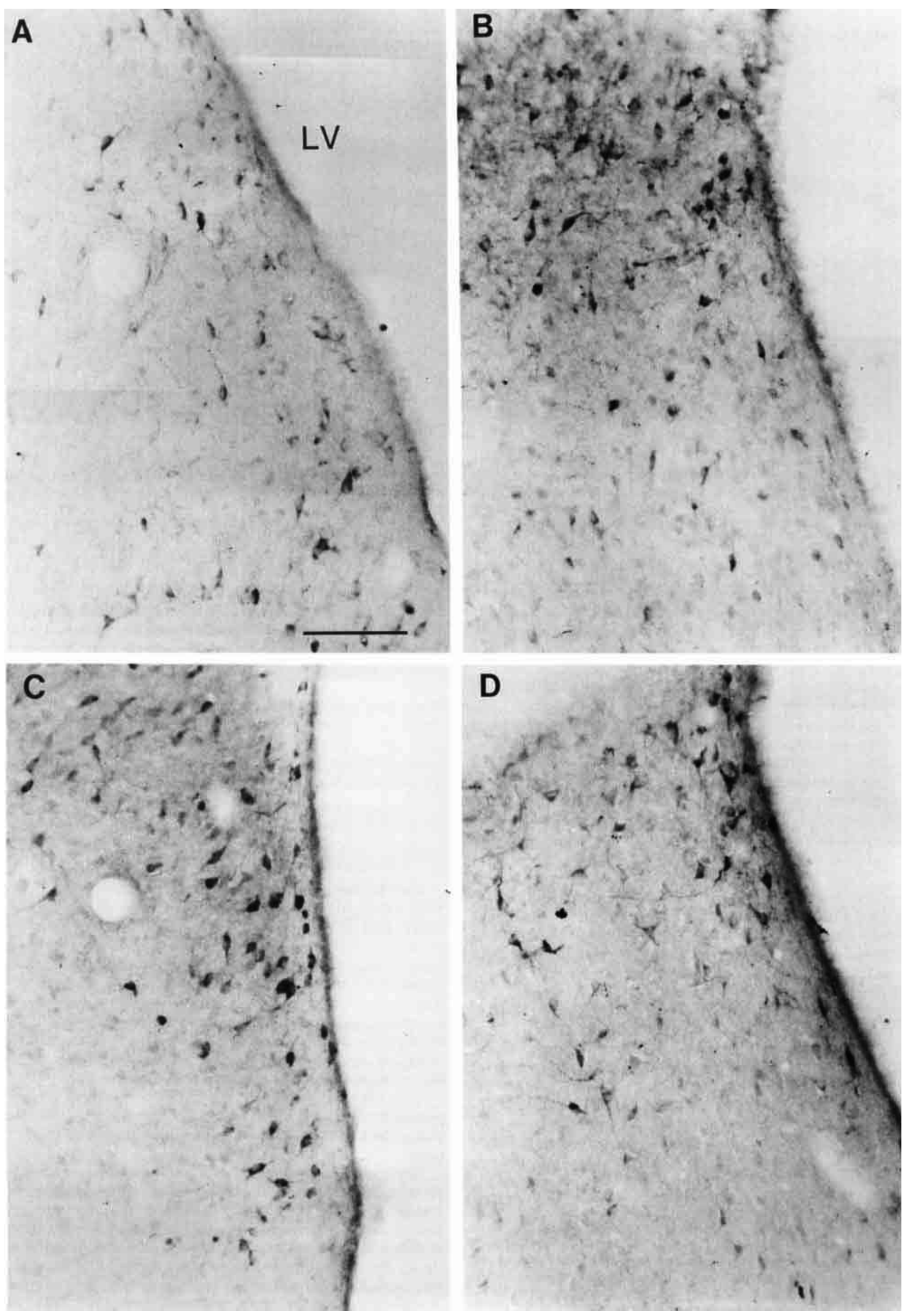


of information when fibers were not clear in the colchicinetreated animals.

In rats and hamsters neither the amount of colchicine nor the survival time had any effect on the patterns of prodynorphin staining reported here. In the rat, $80 \mu \mathrm{g}, 160 \mu \mathrm{g}$, and $320 \mu \mathrm{g}$ colchicine produced identical staining patterns and intensities. In the hamster, the $160 \mu \mathrm{g}$ and $320 \mu \mathrm{g}$ animals were identical in all respects. The $80 \mu \mathrm{g}$ colchicine injection in the hamster produced a similar staining pattern, but the cells were less intensely labeled.

In the rat tissue, all doses of colchicine produced the pattern of immunolabeling that has been described in the literature (Nakao et al., '81, '83b; Khachaturian et al., '82; Palkovits et al., '83; Watson et al., '82a,b, '83; Weber and Barchas, '83; Zamir et al., '83; Smialowski et al., '85; Fallon and Leslie, '86).

Survival time. Although survival times following colchicine injection varied between 24 and 72 hours, a majority of the animals (both rats and hamsters) survived 40-48 hours. Similar patterns of staining were obtained across the entire range of survival times, but $40-48$ hours was the optimal time for maximal intensity of cell staining.

Perfusions. Benzoquinone with $2 \%$ paraformaldehyde was clearly superior to $4 \%$ paraformaldehyde as a fixative for C-peptide immunocytochemical staining. Cell staining was more intense, and cell morphology was more distinct. However, the number and location of labeled cells, fibers, or terminals did not vary with fixative. For immunostaining with dynorphin $\mathrm{A}$ and dynorphin $\mathrm{B}$ both perfusion techniques appeared to work equally well.

Immunohistochemistry procedures. In all hamster and rat sections analyzed, the PAP procedure generated identical immunohistochemical staining patterns to those observed with the indirect immunofluorescence technique. All analysis and mapping of prodynorphin peptides in rat and hamster tissue was therefore performed with PAPstained tissue.

Antisera. The C-peptide, dynorphin A [1-17] and dynorphin $B$ [1-13] antisera produced similar staining patterns. In other words, all areas labeled with the C-peptide antiserum also contained at least some immunolabeled elements (cells, fibers, or terminals) with dynorphin A or dynorphin $\mathrm{B}$ antisera. However, in some brain areas the $\mathrm{C}$ peptide antiserum labeled more cell bodies than the other antisera. The hierarchy of amount and intensity of cell staining in these structures in the hamster was C-peptide > dynorphin $\mathrm{B}>$ dynorphin $\mathrm{A}$ (Fig. $1 \mathrm{~A}-\mathrm{C}$ ), although in a few exceptional areas the C-peptide immunolabeling was not as strong as that of dynorphin B or dynorphin A antisera (Fig.

Fig. 5. Photomicrographs of C-peptide immunoreactivity in various levels of the dorsal part of the lateral septum in the same hamster brain (A-D). A: C-peptide antiserum was not preabsorbed prior to tissue incubation. B: C-peptide antiserum was preabsorbed with $100 \mu \mathrm{M}$ dynorphin A peptide 1 hour prior to tissue incubation. C: C-peptide antiserum was preabsorbed with $100 \mu \mathrm{M}$ dynorphin B peptide 1 hour prior to tissue incubation. D: C-peptide antiserum was preabsorbed with $125 \mu \mathrm{M}$ leuenkephalin peptide 1 hour prior to tissue incubation. Neither the dynorphin nor the enkephalin peptides diminished C-peptide antiserum immunostaining. These sections are from the same brain. The "apparent" lighter lateral septum staining in A results from this section being from a more rostral level of the lateral septum where slightly fewer cells were consistently observed and not from an intensifying effect of the blocking peptides on C-peptide immunostaining. See text for details. Calibration bar equals $100 \mu \mathrm{m}$.
1D-F). Therefore, the C-peptide results were used for the basic analysis and presentation of the prodynorphin distribution in the hamster forebrain reported below. In rat tissue there were no staining differences noted between the three antisera used.

\section{Detection of immunolabeled elements}

With the PAP technique labeled cells could be identified by the dark brown to black diaminobenzidine reaction product filling neuron cell bodies and extending into neuronal cell processes. Though fibers and terminals were not always easy to distinguish from one another there were many instances where immunolabeled fibers with varicosities presented a prominent beaded appearance (Fig. 2A) that could be easily distinguished from the small punctate dots characteristic of terminal labeling (Fig. 2B).

\section{Results of control studies}

The most extensive blocking controls were performed with the novel C-peptide antiserum. The dynorphin A [117) antiserum has been characterized in detail previously (McGinty et al., '83). In all experiments where C-peptide antiserum was incubated for 45 minutes to 1 hour with 5-10 $\mu \mathrm{M}$ rat C-terminus peptide (leumorphin ${ }_{15-29}$ ), all staining was blocked completely (Figs. 3, 4). Porcine C-terminus peptide and human leumorphin peptide showed no blocking effect on rat C-peptide antiserum staining when used at 50 or $100 \mu \mathrm{M}$ concentrations. When the C-peptide, dynorphin A, or dynorphin B antiserum was omitted from the primary solution, immunostaining failed to develop. When the C-peptide antiserum was incubated with $50-100 \mu \mathrm{M}$ dynorphin A [1-17] peptide, dynorphin A [1-13] peptide, dynorphin B [1-13] peptide, leucine-enkephalin peptide, methionine-enkephalin peptide, $\mathrm{ACTH}$ [1-24] peptide, or $\beta$-endorphin peptide prior to staining, C-peptide antiserum immunostaining was not affected (Fig. 5). Only dynorphin A [1-17] peptide had any effect on dynorphin A [AK84T] antiserum staining (blocking it completely at $25 \mu \mathrm{M}$ concentration), and only dynorphin B [1-13] peptide had any effect on either dynorphin B [AK113T] or dynorphin B (\#94, bleed 6) antiserum immunostaining (blocking them completely at $25 \mu \mathrm{M}$ concentration). Dynorphin A [1-13] peptide did not diminish C-peptide staining, dynorphin A [1-17] or dynorphin B [1-13] antiserum staining, even at concentrations of up to $100 \mu \mathrm{M}$.

\section{Species comparisons}

The pattern of immunolabeling we observed was generally similar in many areas of the rat and hamster brain (Figs. $6,7)$. However, in several brain areas distinct species differences between hamster and rat prodynorphin immunolabeling were observed. Areas in which all three antisera labeled more cell bodies in the hamster than in the rat included the medial nucleus of the amygdala and other amygdaloid nuclei, the medial preoptic area, and the bed nucleus of the stria terminalis (Figs. 8, 9). In other areas such as the hippocampal formation and lateral septum, C-peptide and dynorphin $B$ antisera labeled more cells in the hamster than in the rat (Fig. 10), whereas the dynorphin $A$ antiserum produced a pattern very similar to that observed in the rat. Lastly, there were areas in which prodynorphin immunolabeling in the rat brain was consistently more abundant than that observed in the hamster regardless of the antiserum used; these included basal ganglia and related structures and most cortical areas (Fig. 11). 

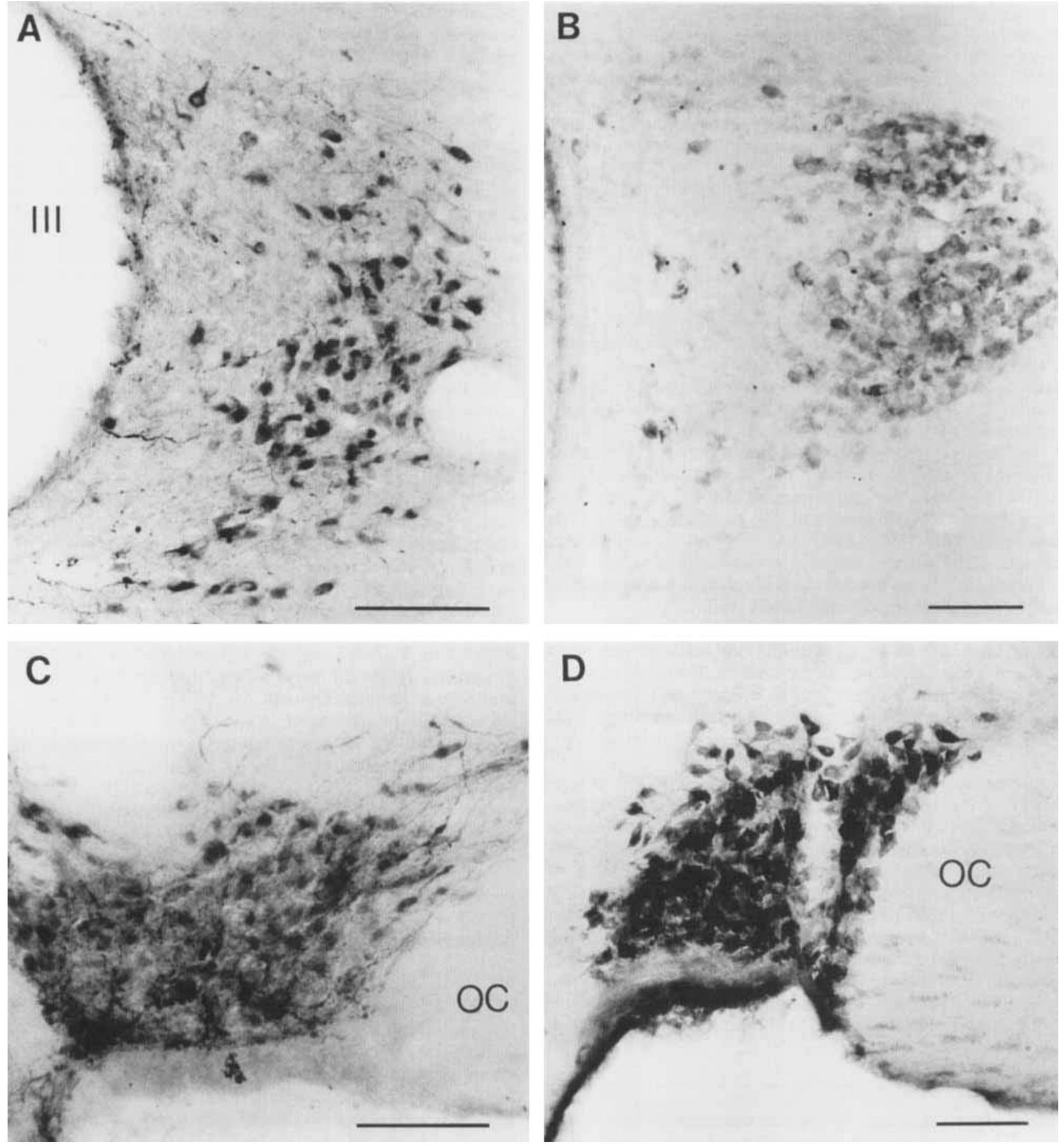

Fig. 6. Photomicrographs of the paraventricular nucleus (A, B) and supraoptic nucleus $(\mathbf{C}, \mathbf{D})$ of the hypothalamus, showing comparisons of C-peptide immunoreactivity in these structures in the hamster (A, C) and in the rat (B, D). Rat and hamster C-peptide immunolabeling are very similar in these areas. Calibration bars equal $100 \mu \mathrm{m}$.

The species comparisons presented below are a result of direct analysis of staining patterns generated by dynorphin $\mathrm{A}$, dynorphin $\mathrm{B}$, and $\mathrm{C}$-peptide antisera in both hamster and rat. In all sections analyzed in this study, no differences were observed between the three antisera in the rat brain but differences between the three antisera in hamster brain were notable. Therefore, differential staining with the three antisera within the hamster, and between rat and hamster, is directly related to differential staining solely within hamster brain material. Though we have made direct com- 

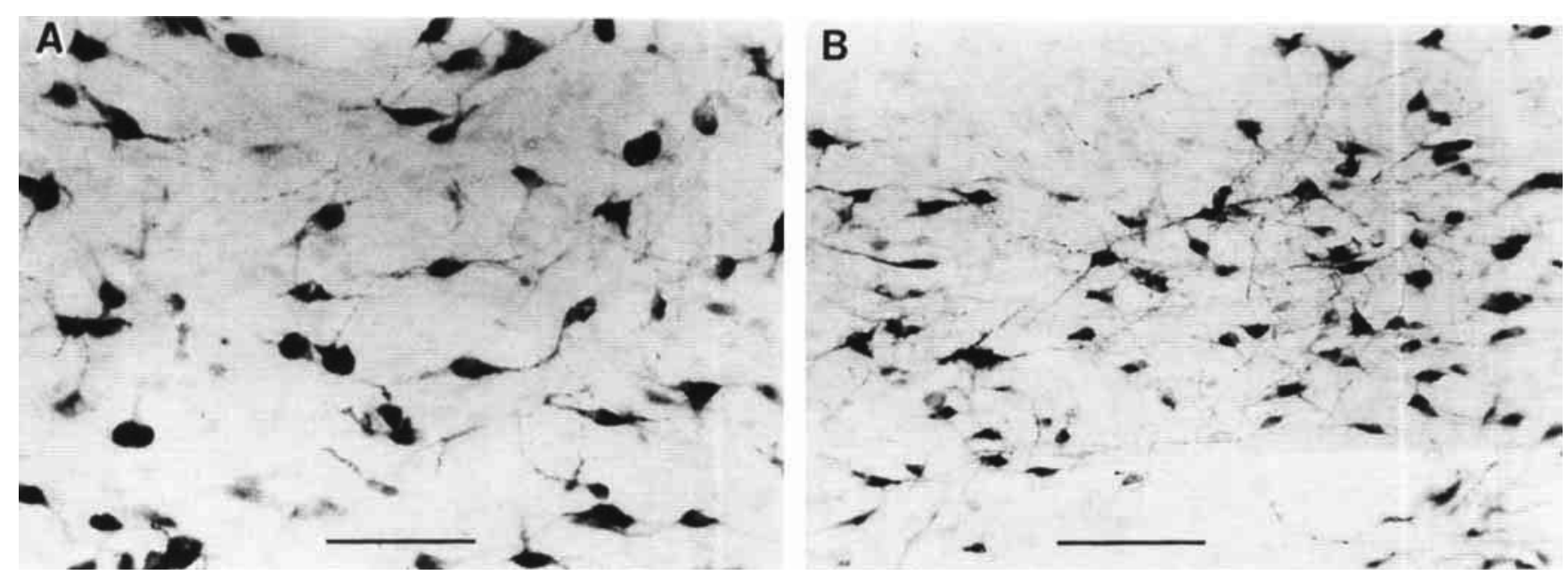

Fig. 7. Photomicrographs of the lateral hypothalamic area (A, B), showing comparisons of C-peptide immunoreactivity in the rat (A) and in the hamster (B). Rat and hamster C-peptide immunolabeling are very similar in this area. Calibration bars equal $100 \mu \mathrm{m}$.

parisons in the text between hamster C-peptide immunostaining and that in the rat, these comparisons hold for all three antisera in the rat (Table 1).

Our findings in the rat with both the Terenius and Watson dynorphin B antisera confirm the dynorphin B labeling reported by Fallon and Leslie ('86) using the Weber dynorphin B antiserum. Therefore, our results in hamster can be directly compared to their dynorphin B immunocytochemical map in rat.

\section{Distribution of prodynorphin staining}

The illustrations of the distribution of prodynorphin staining in the hamster brain (Figs. 12-21) are based on our results with the $\mathrm{C}$-peptide antiserum. These results are compared across species and within species for C-peptide, dynorphin $\mathrm{A}$, and dynorphin $\mathrm{B}$ immunostaining in each region in Table 1.

The prodynorphin neuroanatomical map demonstrates the heaviest staining in limbic structures but also includes the ventral striatum, ventral pallidum, and basal ganglia. Areas showing the most intense and consistent cell staining in the hamster were the anterior continuation of the hippocampus; lateral septum; bed nucleus of the stria terminalis; medial preoptic area; supraoptic, paraventricular, and lateral nuclei of the hypothalamus; medial nucleus of the amygdala; massa intercalata; central, lateral, and basolateral nuclei of the amygdala; CA2, CA3, and CA4 of Ammon's horn; and the dentate gyrus of the hippocampal formation.

Moderate cell staining was observed in the anterior olfactory nucleus; ventral CA1 of Ammon's horn; endopiriform nucleus; anterior, posterolateral, and posteromedial cortical nuclei of the amygdala; ventromedial, dorsal, and posterior hypothalamic areas; periventricular nucleus of the hypothalamus; and ventral premammillary nucleus. Moderate immunolabeling of cells was also found in the ventral striatum (nucleus accumbens, fundus striati, and olfactory tu- bercle) and the ventral pallidum. Lighter-stained cells were found in all remaining areas of allocortex and neocortex, nucleus of the diagonal band of Broca, dorsal striatum, globus pallidus, anterior and dorsal hypothalamic areas, substantia innominata, periventricular and parataenial nuclei of the thalamus, medial habenula, and the parafascicular nucleus.

Labeled fibers were found in many of the same structures but again were heaviest in limbic areas. Terminal staining was, in general, less pronounced than fiber staining throughout the forebrain with a few notable exceptions where it stood out distinctly; these areas included the islands of Calleja, endopiriform nucleus, ventral pallidum, ventromedial part of the medial preoptic nucleus, ventromedial and arcuate nuclei of the hypothalamus, massa intercalata of the amygdala, entopeduncular nucleus, and substantia nigra.

The most consistent and intense staining was in the hypothalamus and preoptic region. By far, the majority of intensely labeled prodynorphin immunoreactive cells, terminals, and fibers found in the forebrain of the hamster were within these two regions.

Hippocampal formation and related structures. Dark cell staining was observed throughout the anterior continuation of the hippocampus (Figs. 13A-14A). Rostrally, fiber staining was strongest in the dorsal part of the anterior continuation of the hippocampus. Caudally, both fibers and cells spread laterally to blend with the intermediate lateral septum just ventral to the infralimbic cortex at the genu of the corpus callosum. Distinct cell staining and light terminal and fiber staining was observed in the indusium griseum throughout its rostral to caudal extent (Figs. 14B-19B).

Dense immunostaining was observed in all parts of the granule cell layer of the dentate gyrus (Figs. 4A, 10A). This layer was so heavily labeled when using C-peptide antiserum that it was difficult to clearly distinguish immunolabeled cells from fibers or terminals (Figs. 17B-21), though in some sections labeled granule cells could be identified. In sections from noncolchicine-treated brains, heavy mossy fi- 


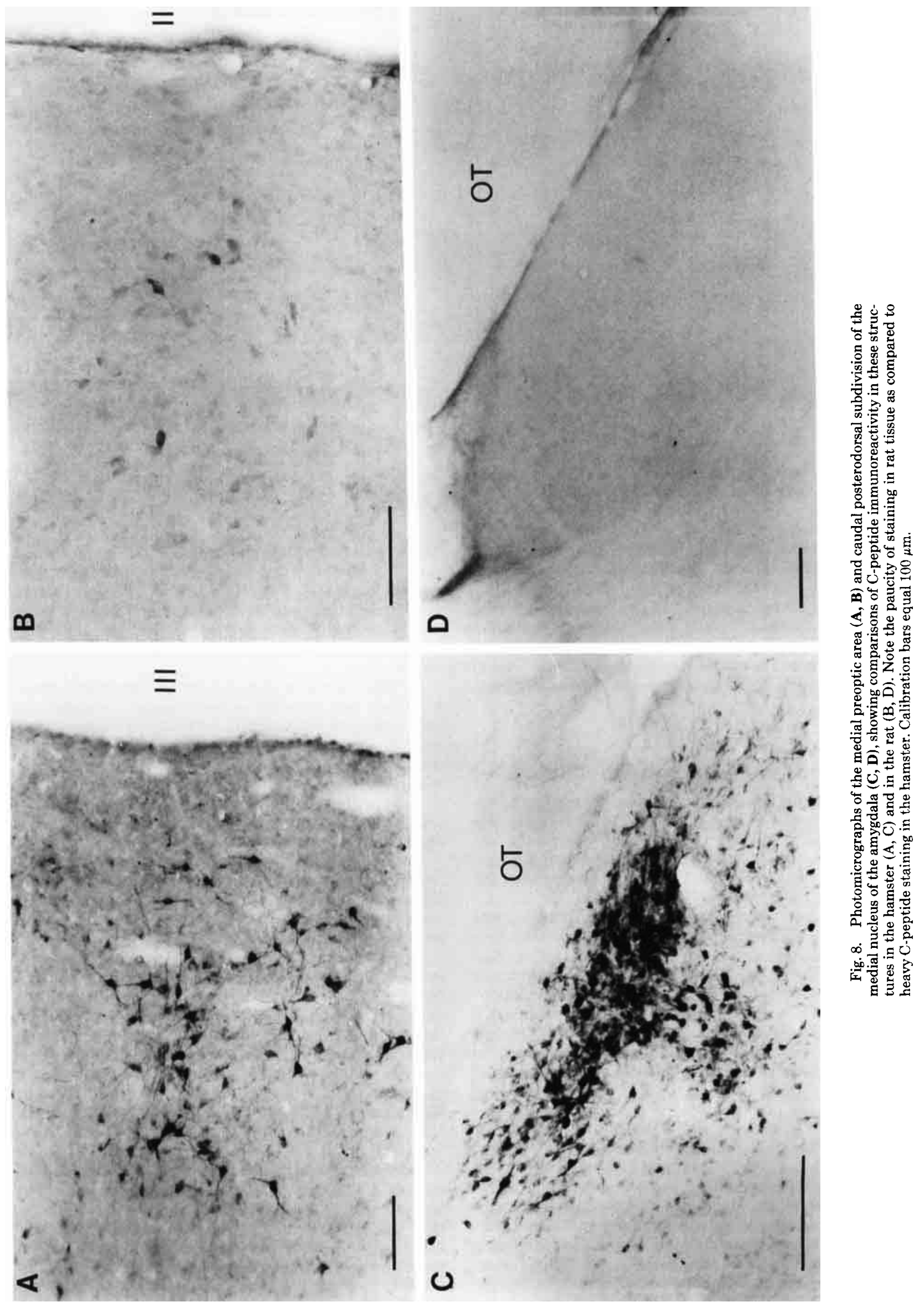



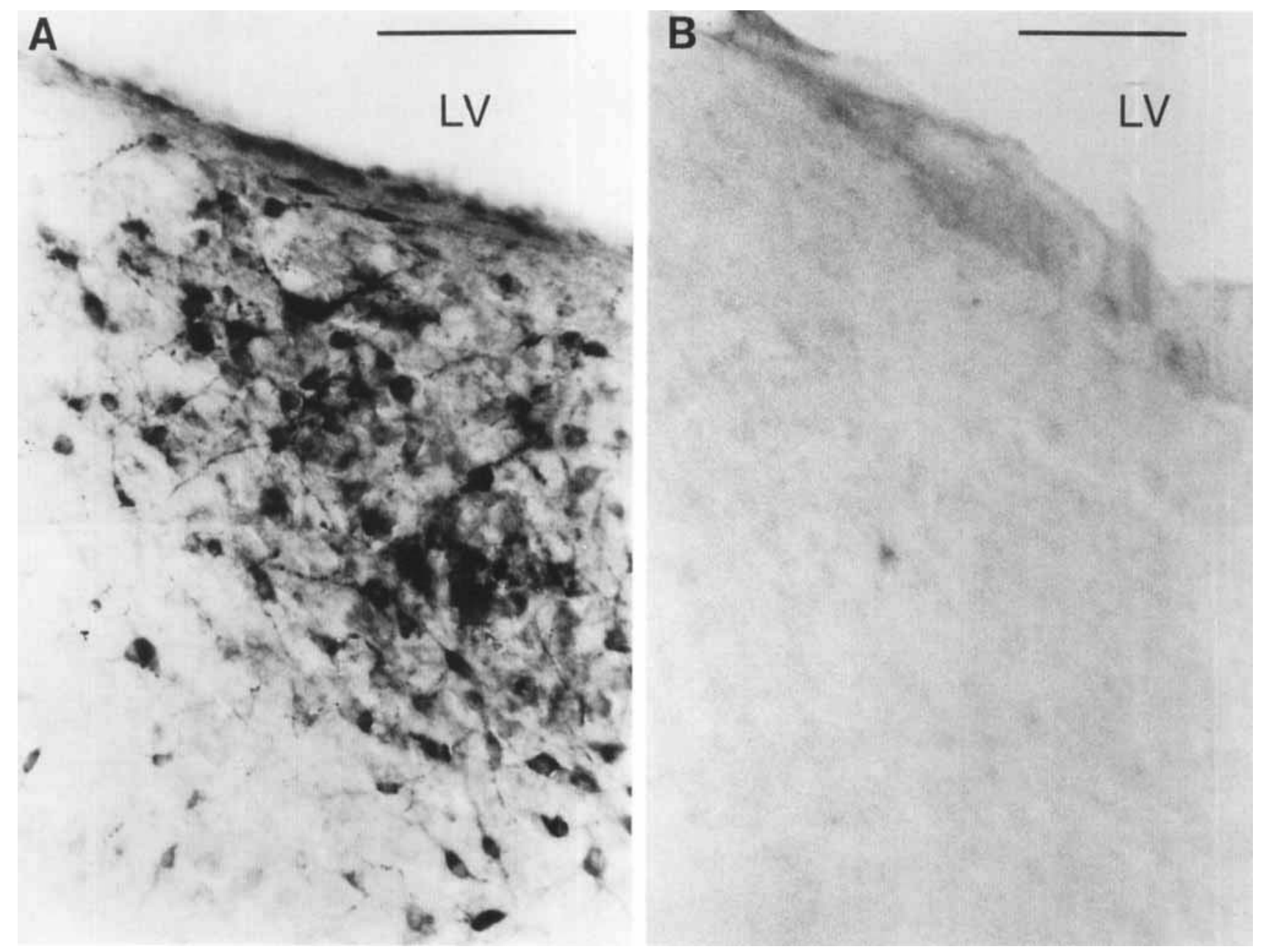

Fig. 9. Photomicrographs of the medial part of the bed nucleus of the stria terminalis (A, B), showing comparisons of C-peptide immunoreactivity in this structure in the hamster (A) and in the rat (B). Note the paucity of staining in rat tissue as compared to heavy C-peptide staining in the hamster. Calibration bars equal $100 \mu \mathrm{m}$.

ber staining was observed over the hilar region, with staining in dentate gyrus diminished.

Fiber and granule cell staining in the pyramidal cell layer of Ammon's horn was prominent in CA1, CA2, and CA3 rostrally (Fig. 18B). Caudally CA1 staining decreased considerably (Figs. 19B-21), while CA2 staining became slightly diminished and $\mathrm{CA} 3$ staining remained consistently strong. At all levels CA4 had scattered distinctly labeled cells (Figs. $4 \mathrm{~A}, 10 \mathrm{~A}, 18 \mathrm{~B}-21$ ). Fibers of the alveolus were lightly stained.

In hamsters dynorphin A and dynorphin B immunostaining patterns were similar to C-peptide in the anterior continuation of the hippocampus, though labeled cells were fewer in number and lighter in intensity. Light clouds of terminals and fibers, but no cells, were labeled throughout the indusium griseum. In the anterior continuation of the hypothalamus and indusium griseum of the rat, no staining differences were noted from those observed in hamster with C-peptide antiserum. In the hippocampus, however, both species and antiserum affected the type of staining observed. C-peptide antiserum in rat tissue gave staining similar to that reported previously in the hippocampal formation, with no cells but heavy mossy fiber staining in area CA4 (Fig. 10), light granule cell label in dentate gyrus, and light fiber staining in CA2 and CA3. In the hamster, in contrast to C-peptide immunoreactivity, antisera to dynorphin $A$ and dynorphin B produced no CA4 cell staining; this region was filled only with a cloud of stained fibers and terminal fields. In CA2 and CA3, granule cells were sparsely labeled, with moderate fiber and terminal staining when using the dynorphin B antiserum. With the dynorphin A antiserum, no granule cells were labeled, but labeled fibers and terminals were prominent. Both $\mathrm{CA} 1$ and dentate gyrus granule cell layer immunolabeling was weak with dynorphin $\mathrm{B}$ and dynorphin $\mathrm{A}$ antisera in the hamster.

Anterior olfactory nucleus. In hamster, dynorphin A and $\mathrm{B}$ and $\mathrm{C}$-peptide antisera produced many moderately labeled cells and fibers in the medial and ventral parts of the 


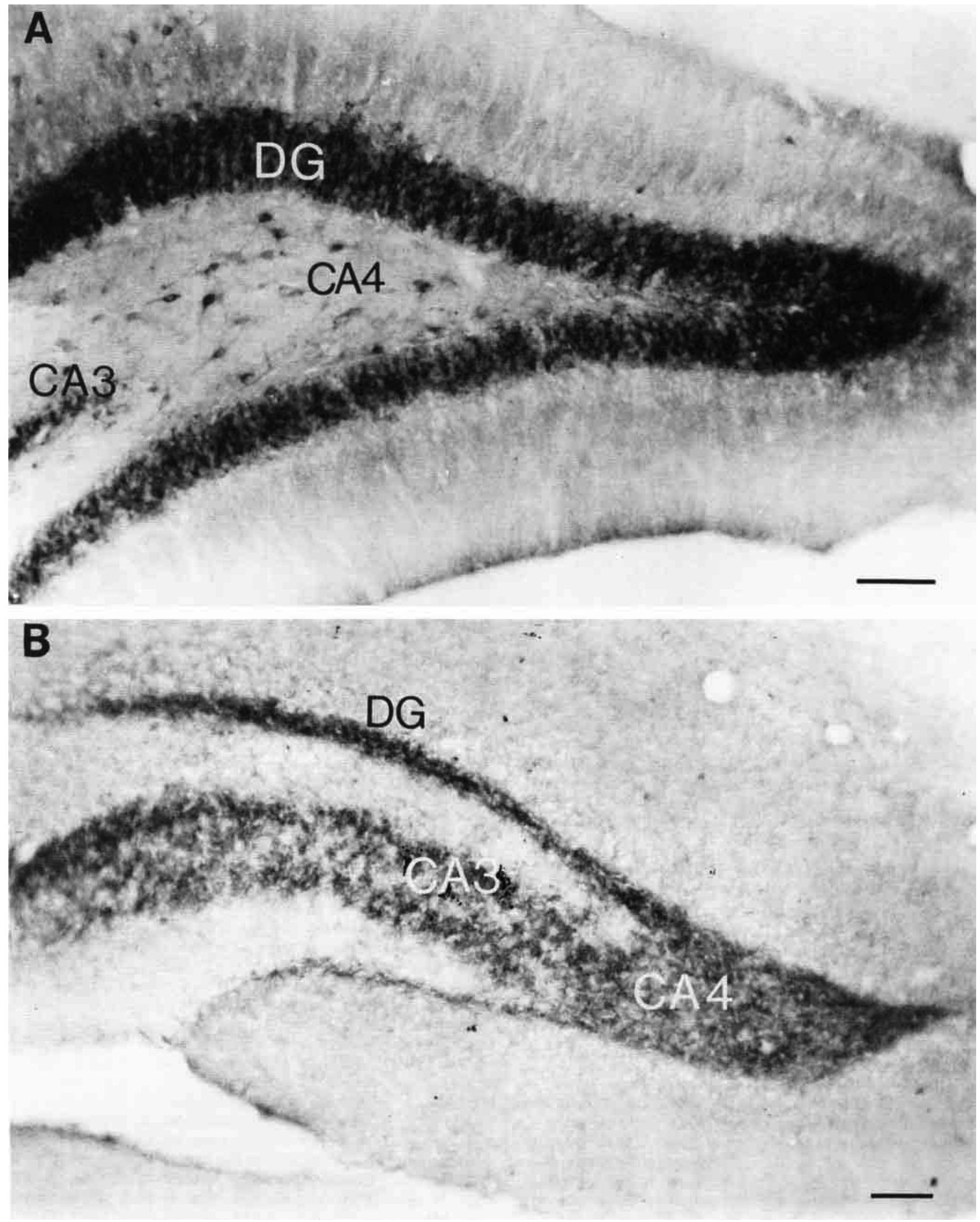




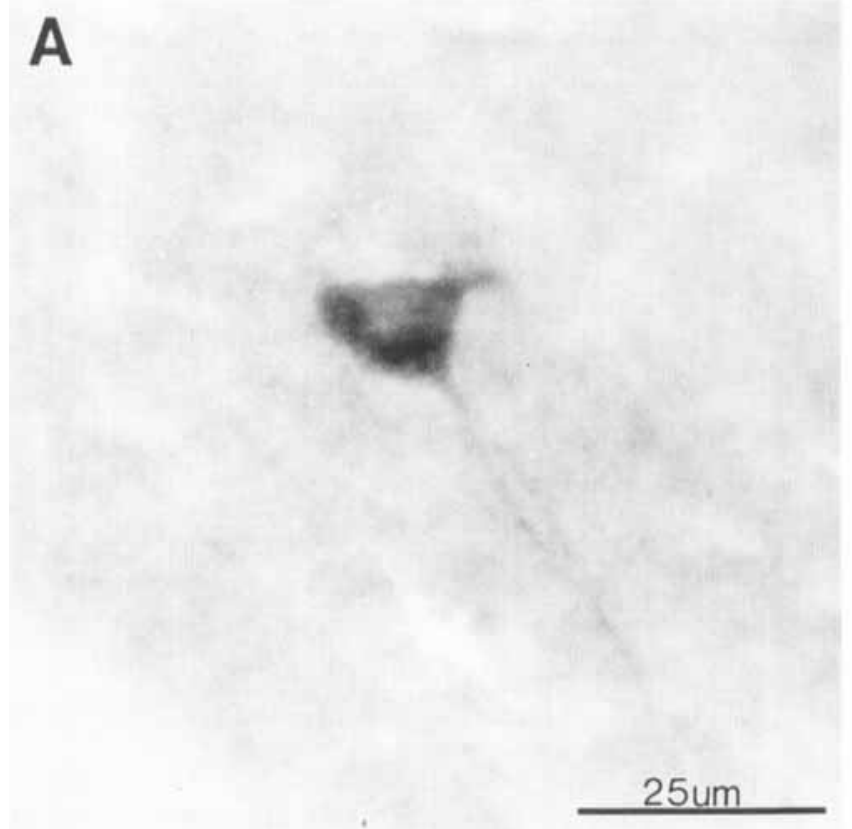

B

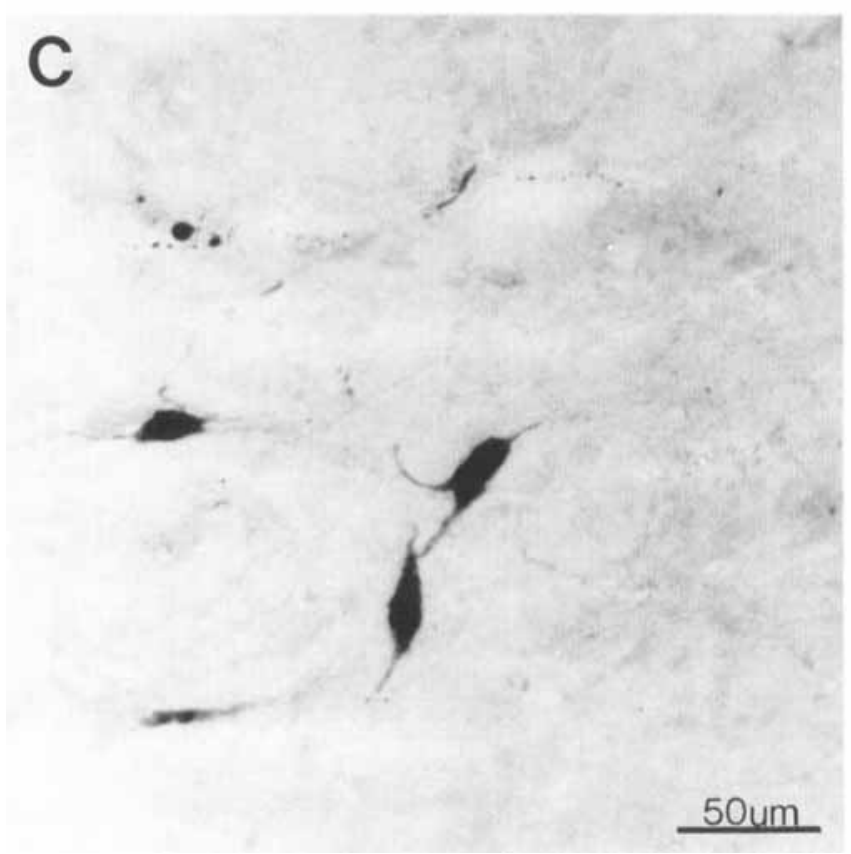

\section{I}

Fig. 11. Photomicrographs of C-peptide immunostaining in the cortex and globus pallidus of the hamster and rat. Though fewer in number, immunolabeled neurons in hamster neocortex (A) were as easily distinguished as the more numerous cortical neurons in the rat (B). In the

anterior olfactory nucleus, with a few lightly staining cells extending into the dorsal part (Fig. 12A,B). The posterior anterior olfactory nucleus contained scattered labeled cells (Fig. 13A), which disappeared ventral to the nucleus ac-

Fig. 10. Photomicrographs of the dentate gyrus/CA4 region of the hippocampal formation (A, B) showing comparisons of C-peptide immunoreactivity in these structures in the hamster $(\mathbf{A})$ and in the rat (B). Calibration bars equal $100 \mu \mathrm{m}$.

globus pallidus both hamster (C) and rat (D) neurons were darkly labeled, but such pallidal neurons were more numerous in the rat. Also, fiber staining in this area was greater in the rat than in the hamster.

cumbens. The anterior olfactory nucleus in the rat also had numerous immunolabeled cells and fibers, demonstrating a similar immunoreactive pattern to that of the hamster.

Cortex. Moderately stained cells were scattered singly throughout the rostral to caudal extent of both the allocortex and neocortex (Fig. 11A). In the neocortex, immunolabeling appeared to be confined to pyramidal cells in layers III and V. Most rostrally, staining was confined to the ventral and medial orbital cortex (Fig. 12B). There were lightly 
TABLE 1. Comparisons of Immunohistochemical Staining of Nerve Cell Bodies (Cells), Fibers, and Terminals (F/T) in Several Forebrain Regions of the Hamster and Rat Using C-peptide, Dynorphin B, and Dynorphin A Antisera $(-=$ None; $+=$ Sparse; $++=$ Light; $+++=$ Moderate; $++++=$ Dense;

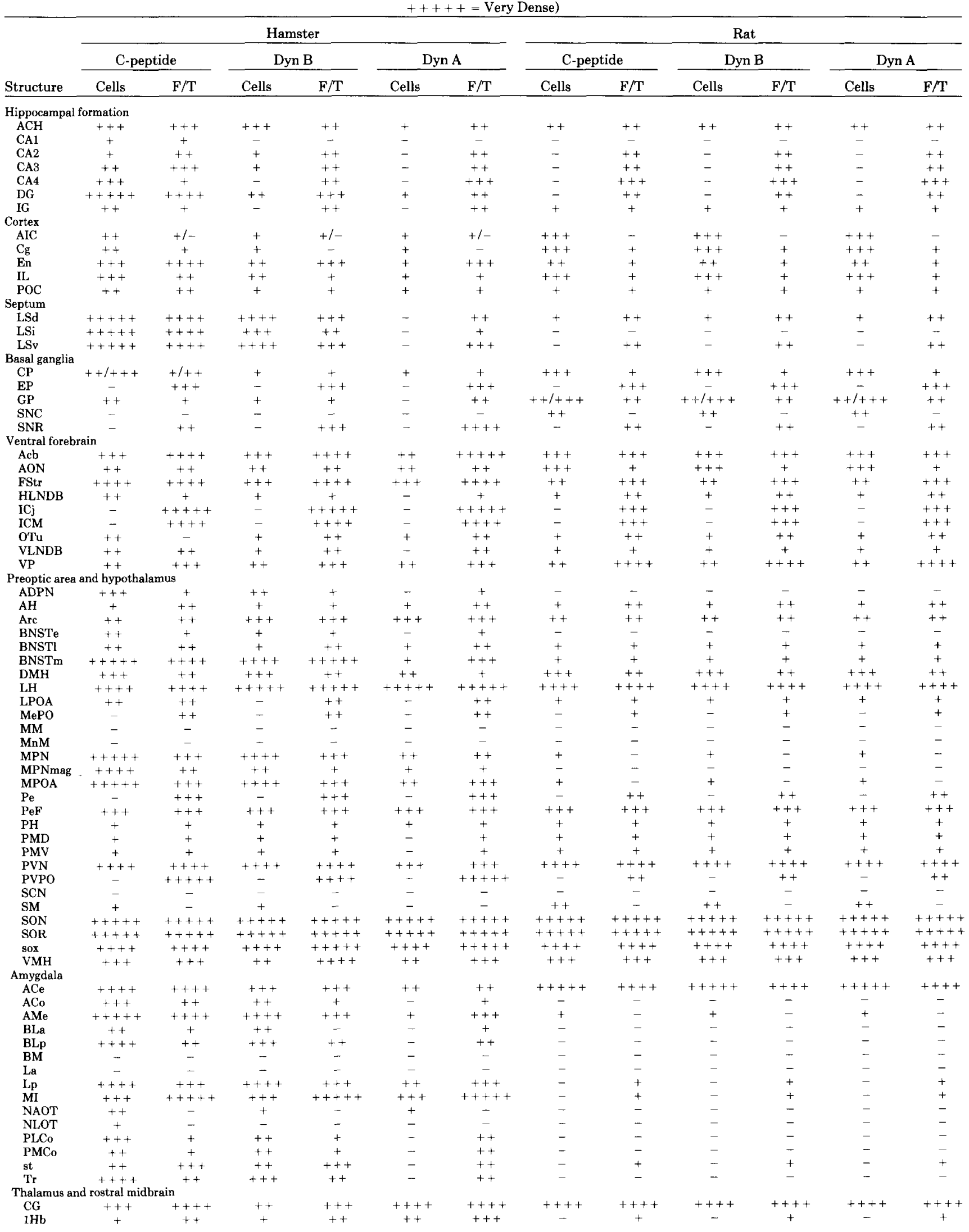


TABLE 1. continued

\begin{tabular}{|c|c|c|c|c|c|c|c|c|c|c|c|c|}
\hline \multirow[b]{3}{*}{ Structure } & \multicolumn{6}{|c|}{ Hamster } & \multicolumn{6}{|c|}{ Rat } \\
\hline & \multicolumn{2}{|c|}{ C-peptide } & \multicolumn{2}{|c|}{ Dyn B } & \multicolumn{2}{|c|}{ Dyn A } & \multicolumn{2}{|c|}{ C-peptide } & \multicolumn{2}{|c|}{ Dyn B } & \multicolumn{2}{|c|}{ Dyn A } \\
\hline & Cells & $\mathrm{F} / \mathrm{T}$ & Cells & $\mathrm{F} / \mathrm{T}$ & Cells & $\mathrm{F} / \mathrm{T}$ & Cells & $\mathrm{F} / \mathrm{T}$ & Cells & $\mathrm{F} / \mathrm{T}$ & Cells & $\mathrm{F} / \mathrm{T}$ \\
\hline $\mathrm{mHb}$ & - & ++ & - & ++ & - & +++ & - & + & - & + & - & + \\
\hline PrC & + & + & ++ & ++ & ++ & +++ & - & - & - & - & - & - \\
\hline PIL & ++ & + & ++ & + & ++ & + & - & - & - & - & - & - \\
\hline $\begin{array}{l}\text { PPN } \\
\text { PT }\end{array}$ & $\begin{array}{c}+++ \\
++\end{array}$ & $\begin{array}{c}+++ \\
++++\end{array}$ & $\begin{array}{c}+++ \\
++\end{array}$ & $\begin{array}{c}+++ \\
++++\end{array}$ & +++++ & $\begin{array}{c}+++ \\
++++\end{array}$ & $\begin{array}{c}+++ \\
-\end{array}$ & $\begin{array}{c}++ \\
++\end{array}$ & $\begin{array}{c}+++ \\
-\end{array}$ & $\begin{array}{c}++ \\
+++\end{array}$ & $\begin{array}{c}+++ \\
-\end{array}$ & $\begin{array}{l}++ \\
+++\end{array}$ \\
\hline
\end{tabular}

stained cells in the infralimbic cortex, diminishing dorsally into the cingulate cortex (Fig. 13A,B). More distinct cell and fiber staining continued caudally in the infralimbic cortex (Fig. 13B), disappearing rostral to the genu of the corpus callosum. Labeled infralimbic cells were in layers II-IV, most numerous in layer II.

The primary olfactory cortex showed scattered fiber and cell staining throughout its rostrocaudal extent (Figs. 13A20A). The heaviest staining was near the rhinal sulcus where it continued dorsally into the anterior agranular insular cortex at rostral levels (Figs. 13B, 14A). The posterior part of the agranular insular cortex contained scattered immunoreactive cells in the deeper layers (Figs. 19A-21).

Terminal staining was evident in the medial part of the primary olfactory cortex but minimal or absent in all other cortical regions. Several distinctly stained cells surrounded by a cloud of terminals were observed at each level of the ventral part of the dorsal endopiriform nucleus.

Dynorphin A and B immunoreactive cells were scattered in all areas of the cortex described above. However, the number of cells stained with these antisera was clearly less than that observed with C-peptide staining. This difference was much more pronounced rostral to the genu of the corpus callosum, where C-peptide cortical staining was strongest.

In the rat cortex, the distribution of labeled cells was similar to that described previously (McGinty et al., '83; Fallon and Leslie, '86). In all cortical areas, with the exception of the primary olfactory cortex, there were more immunolabeled cells in the rat with all three antisera than in the hamster (Fig. 11B). In the primary olfactory cortex all three antisera produced much less intense staining, with fewer cell bodies labeled than with C-peptide antiserum in the hamster.

Septum. A cluster of darkly stained cells and fibers appeared medial to the lateral ventricle at the emergence of the intermediate lateral septum (Fig. 14A). A few single, darkly stained cells and light single fibers also appeared medially in the intermediate lateral septum at more caudal levels (Figs. 14B-15B). Caudally, cells and fibers filled the dorsal lateral septum (Figs. 5, 14B-16A). Cell staining extended into the ventral lateral septum, with less fiber staining in this region (Figs. 14B, 15A). This septal labeling extended ventrally into the nucleus accumbens rostrally and into the bed nucleus of the stria terminalis at more caudal levels. Terminal staining was light and only observed at rostral levels of the intermediate and ventral parts of the lateral septum.

With dynorphin B antiserum, cell body staining in the more medial aspects of dorsal lateral septum was absent, and fewer labeled cells were found throughout the septum. Dynorphin A antiserum, on the other hand, produced quite a different pattern from dynorphin $B$ and C-peptide, showing consistent terminal clouds and scattered fibers, but only occasional, single, scattered cells at all levels of the lateral septum.
In addition, rat immunostaining was very different from that in the hamster. Only very lightly labeled cells were observed, and these were few in number and confined to the most laterodorsal corner of the dorsal lateral septum. Fiber staining was darker, but fibers were less numerous than in the hamster.

Basal ganglia. Medium-sized, weakly stained cells and fibers were diffusely and sparsely distributed throughout the hamster caudate-putamen (Figs. 14A-19B). Terminal stain was negligible except in the caudal dorsal striatum, where prodynorphin cells and fibers were stained in in creased numbers and intensity (Figs. 18A-19A). C-peptidelabeled cells in caudate-putamen varied in size, but the intensity of staining remained relatively light at all levels.

Dynorphin A and B antisera stained even fewer cells in the striatum than the C-peptide antiserum, with cells mostly in the medial caudate-putamen and light in intensity. Rat immunostaining showed numerous scattered cells throughout the dorsal striatum.

In the globus pallidus of the hamster, immunostaining of both cells and fibers was moderate at rostral levels (Fig. 11C) and diminished considerably in the caudal part. Globus pallidus cell staining was less abundant and more intense than that of the caudate-putamen. Fiber staining, though present, was very light in this region. Fiber and terminal staining was observed in the rostral entopeduncular nucleus (Fig. 20B), forming a mossy-like cloud over the nucleus.

Dynorphin $A$ antiserum labeled fibers and terminals more heavily than C-peptide in globus pallidus, but no immunolabeled cells were observed. Dynorphin B antiserum labeled occasional cells, but fewer than C-peptide. In the rat, on the other hand, C-peptide antiserum stained numerous large cells and prominent fibers in globus pallidus (Fig. 11D). These immunolabeled cells, though no more intensely stained, were much more numerous than with any dynorphin antiserum in the hamster. The fiber and terminal stain formed a pattern over this nucleus similar to but less intense than that observed with C-peptide in hamster entopeduncular nucleus as described above. This staining pattern in the entopeduncular nucleus resembled the enkephalinergic "woolly fibers" described in the ventral pallidum in a previous immunocytochemical study (Haber and Nauta, '83).

Substantia nigra staining with C-peptide antiserum in the hamster was consistently confined to terminals and a few fibers in the pars reticulata giving this same "woolly fiber" appearance described above. There was no staining in pars compacta (Fig. 21). Antisera to dynorphin A and B consistently showed heavier pars reticulata fiber and terminal labeling than with $\mathrm{C}$-peptide, but again, no pars compacta staining. In the rat all three antisera lightly labeled scattered cell bodies dorsal and lateral to pars compacta, as well as fibers and terminals in pars reticulata.

Ventral striatum and pallidum. The rostral pole of nucleus accumbens contained small, distinctly labeled cells 


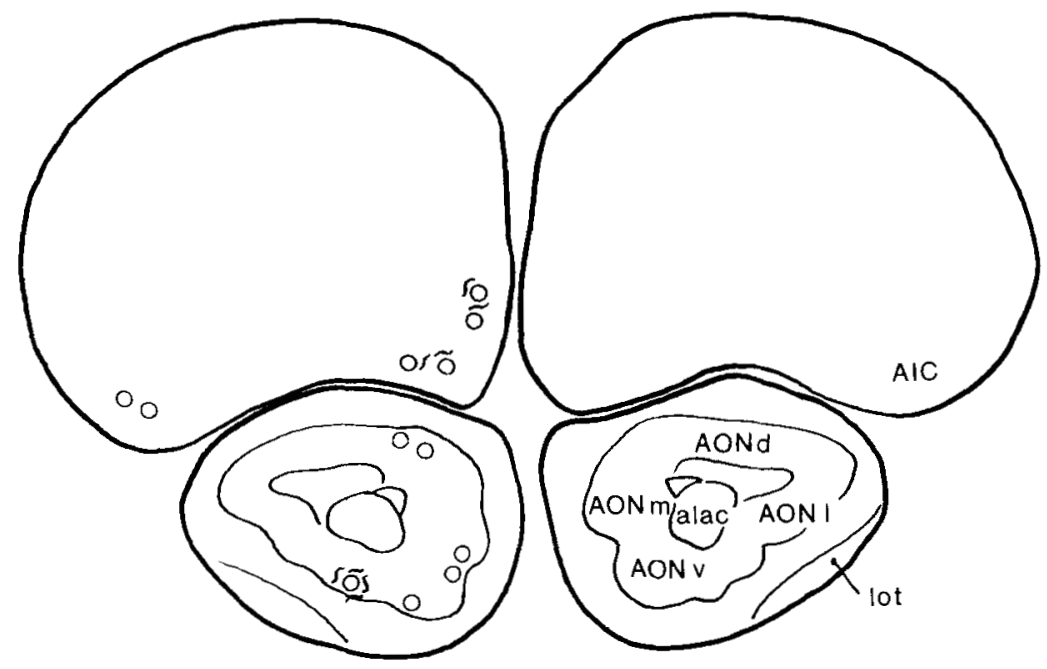

A

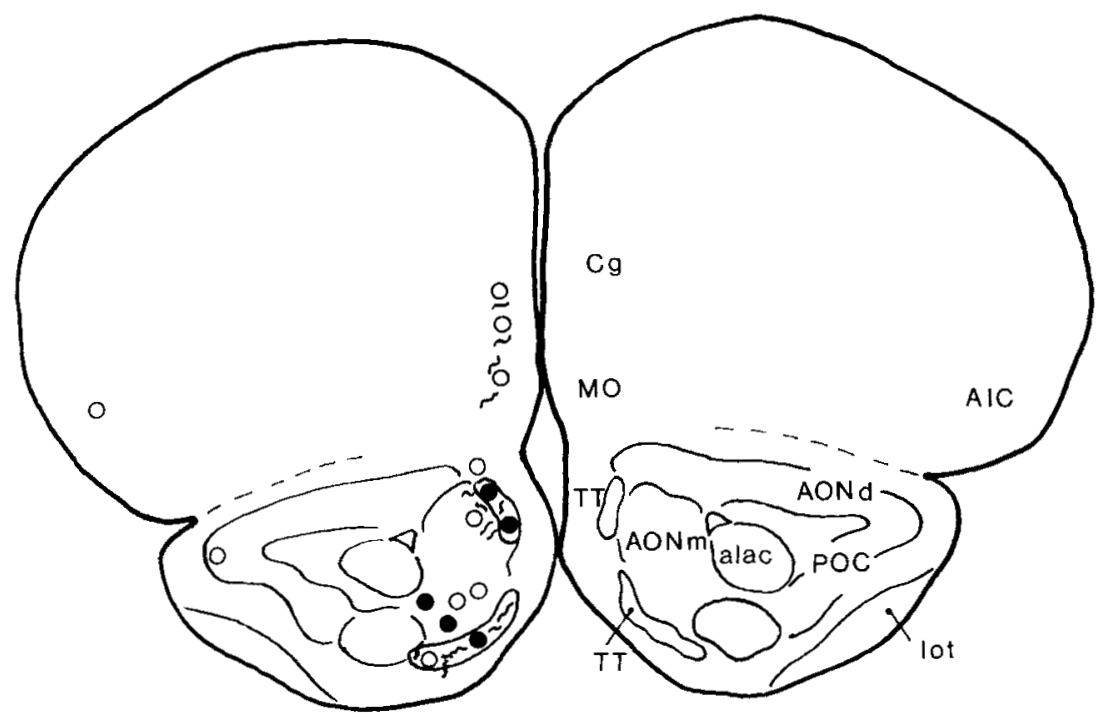

B

Figs. 12-21. Plots of C-peptide immunoreactivity in successive coronal sections of the male Syrian hamster brain. Fibers are represented by short black lines, terminal fields by black dots, darkly labeled cell bodies by filled black circles, and lightly labeled cell bodies by open cir- cles. Only the most heavily labeled terminal fields are illustrated. Plots of immunolabeled elements represent a synthesis of material observed in all animals studied. 


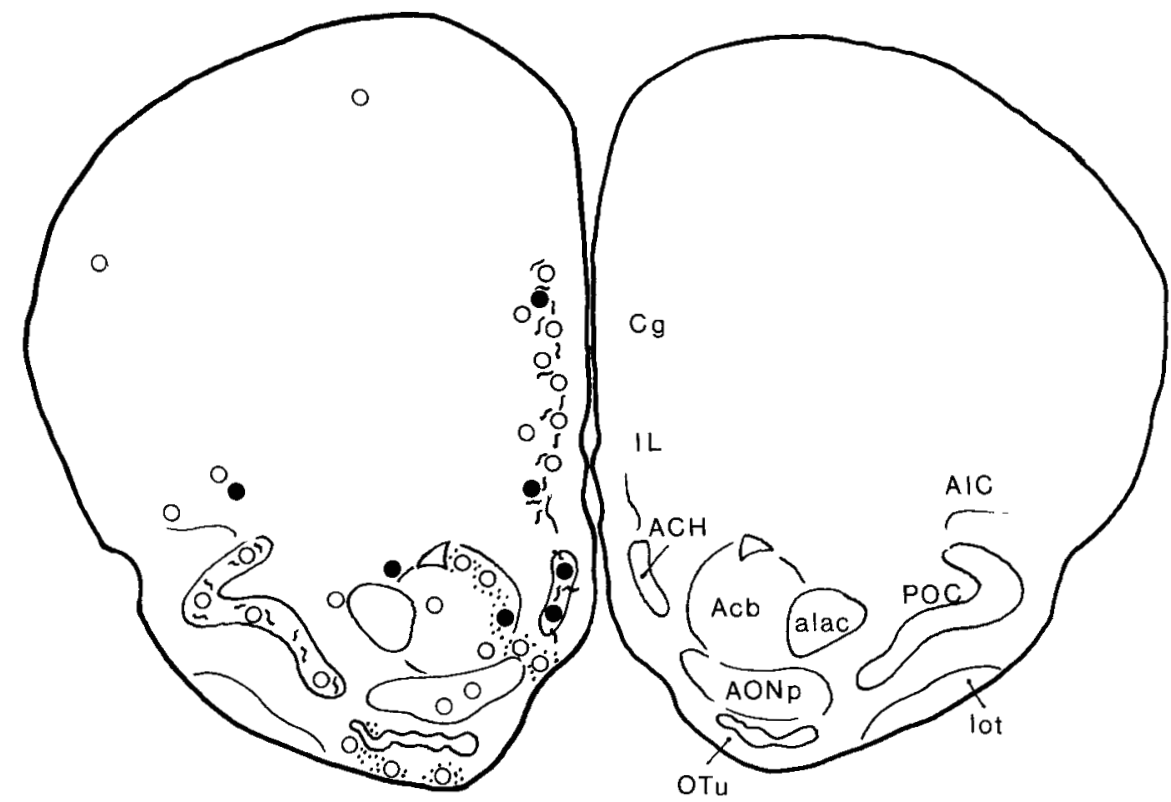

A

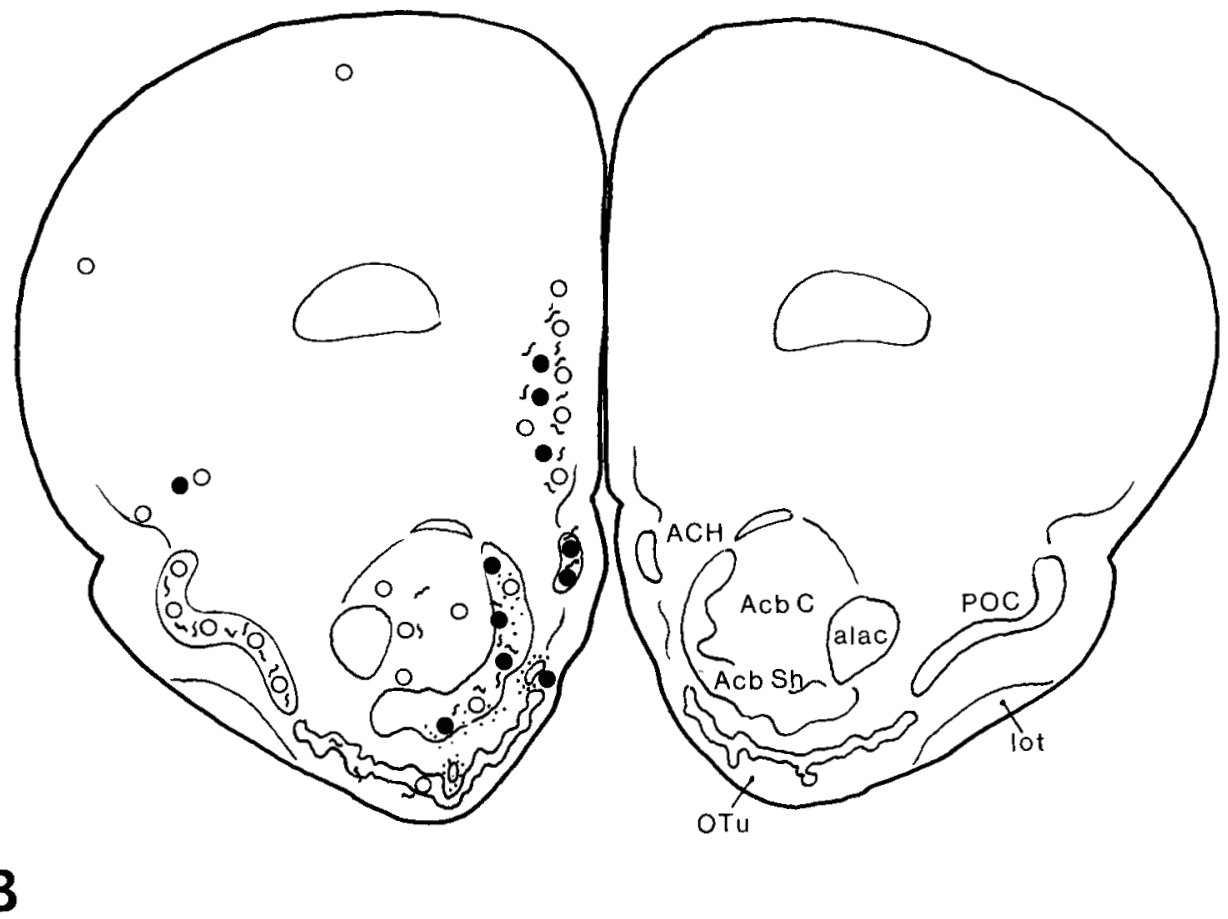

Figure 13 


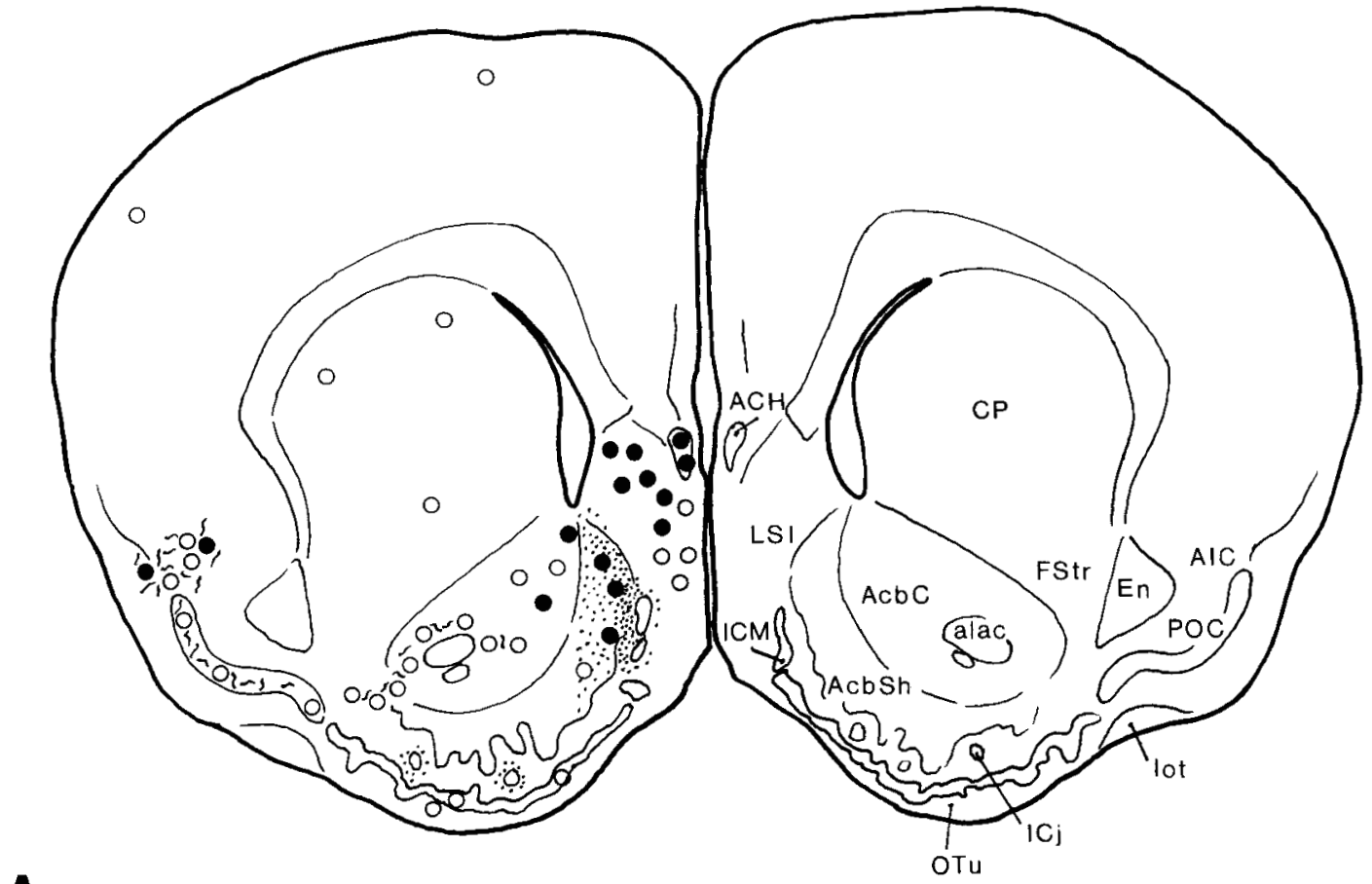

A

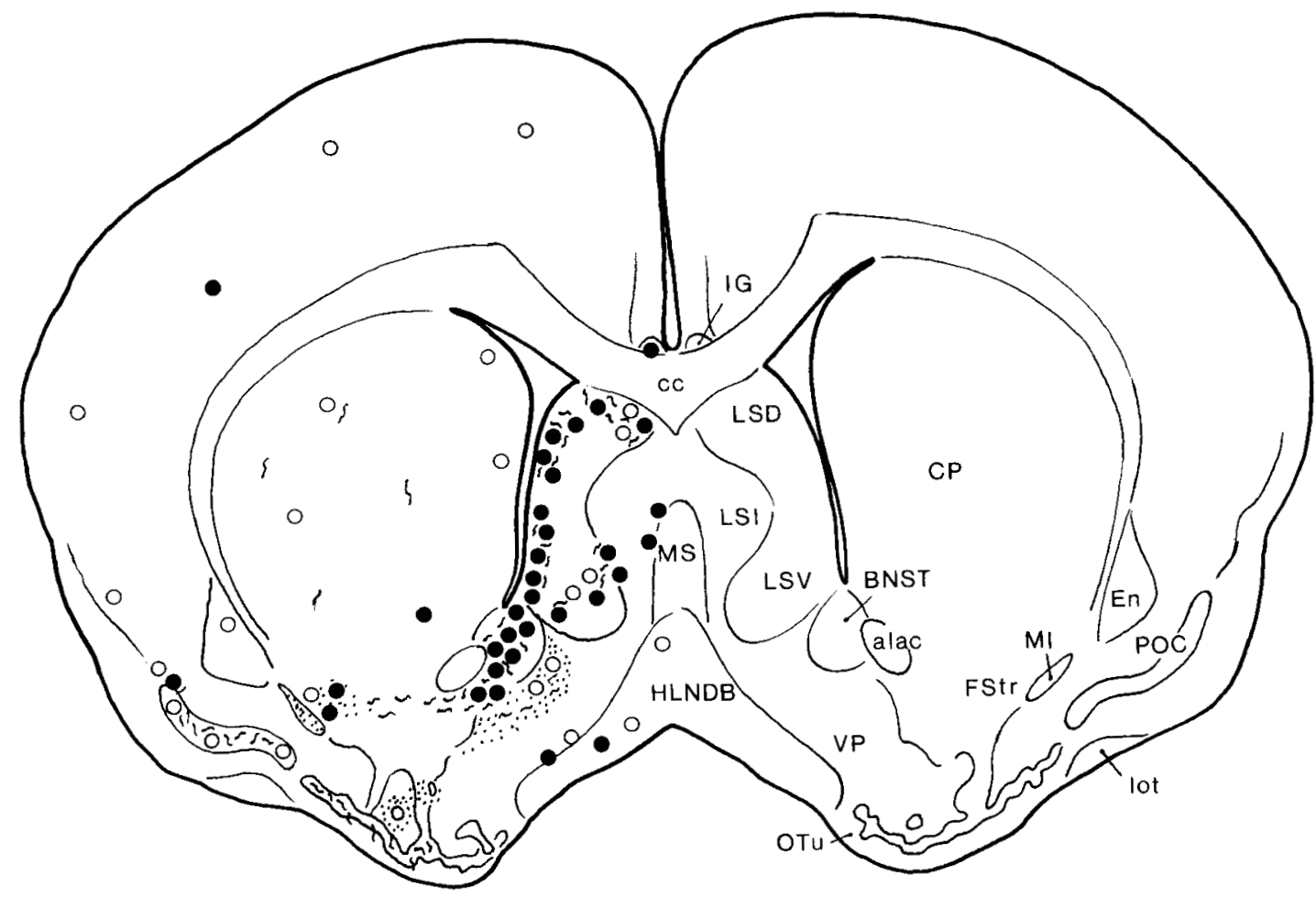

B

Figure 14 

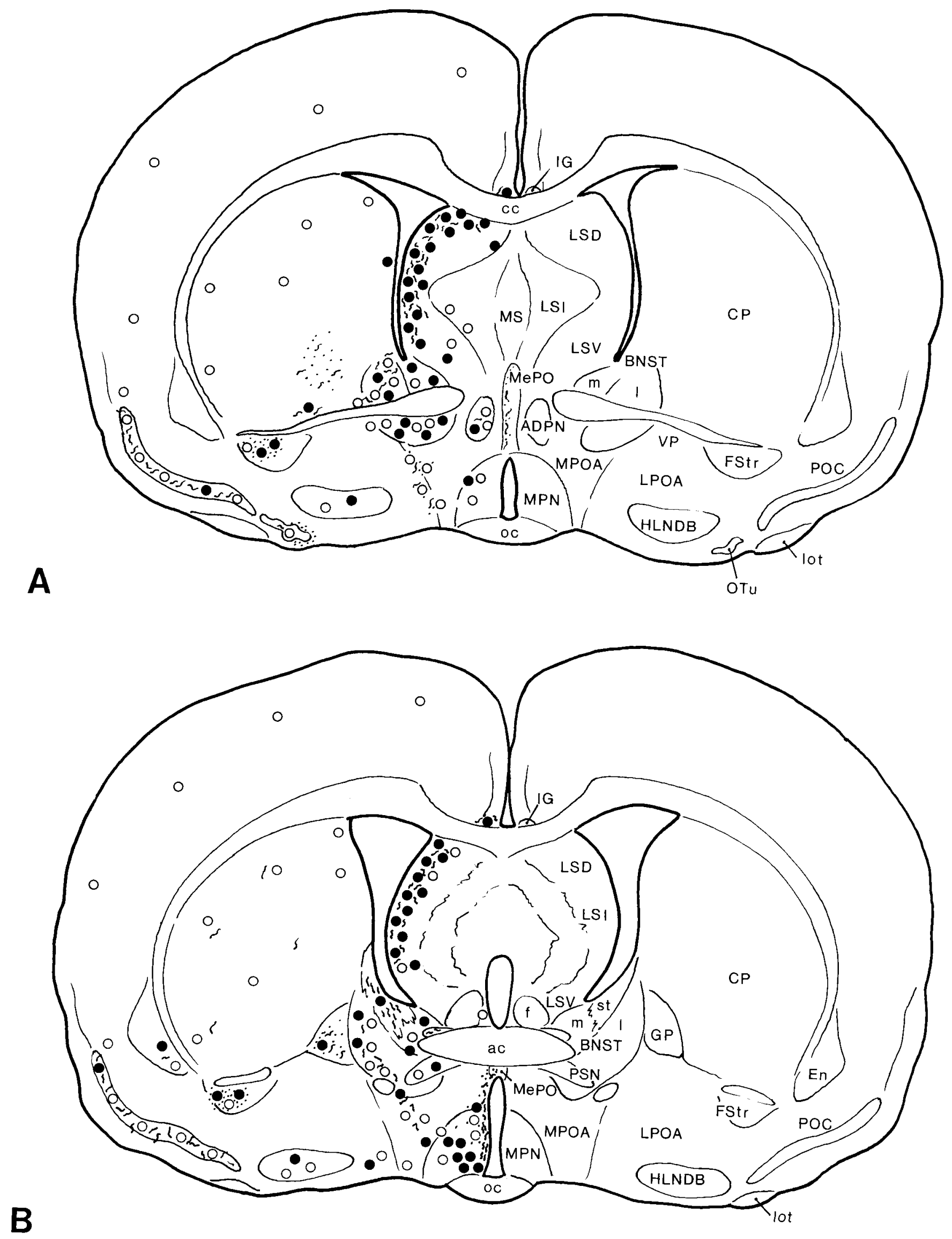

Figure 15 


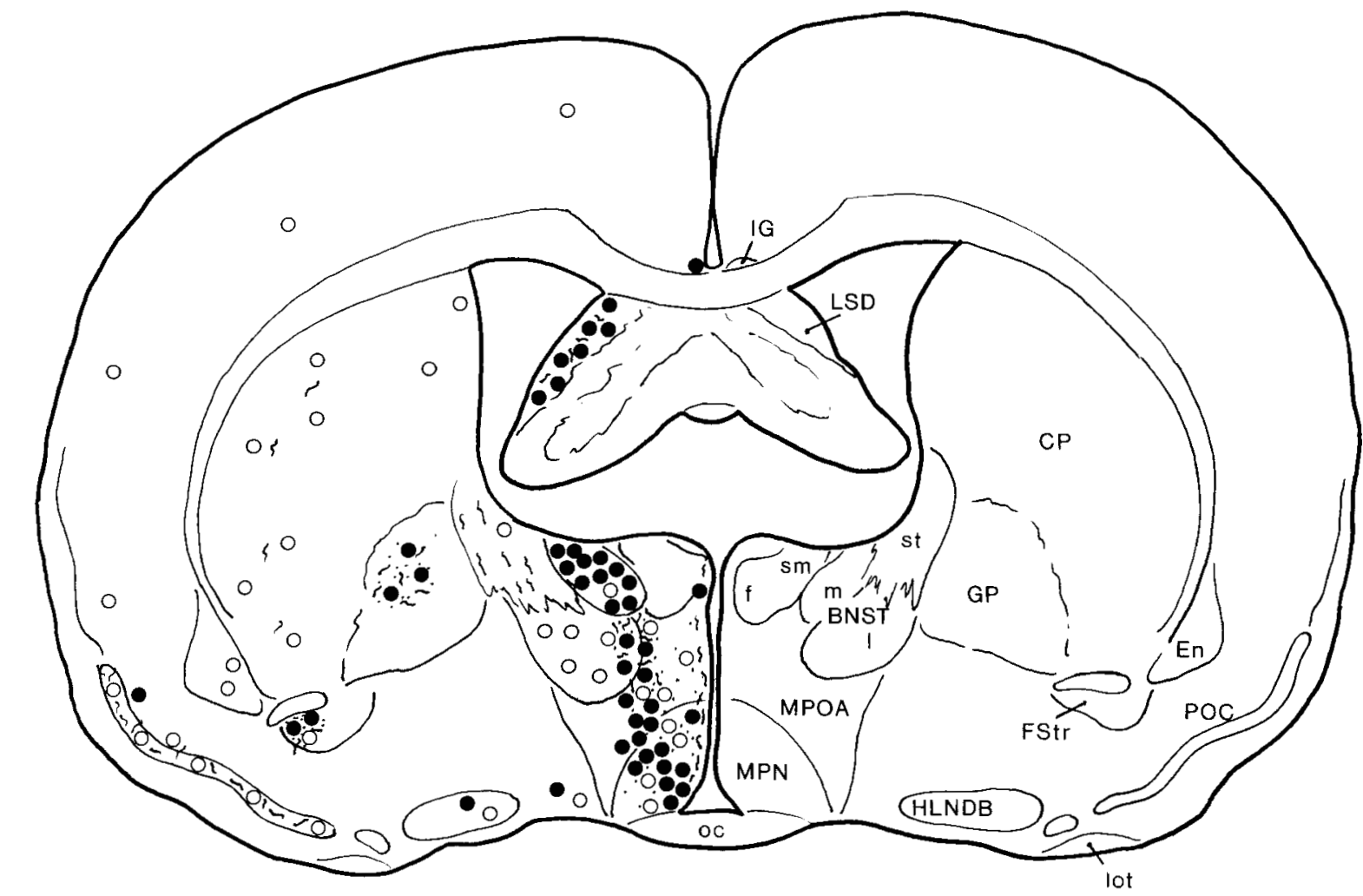

A

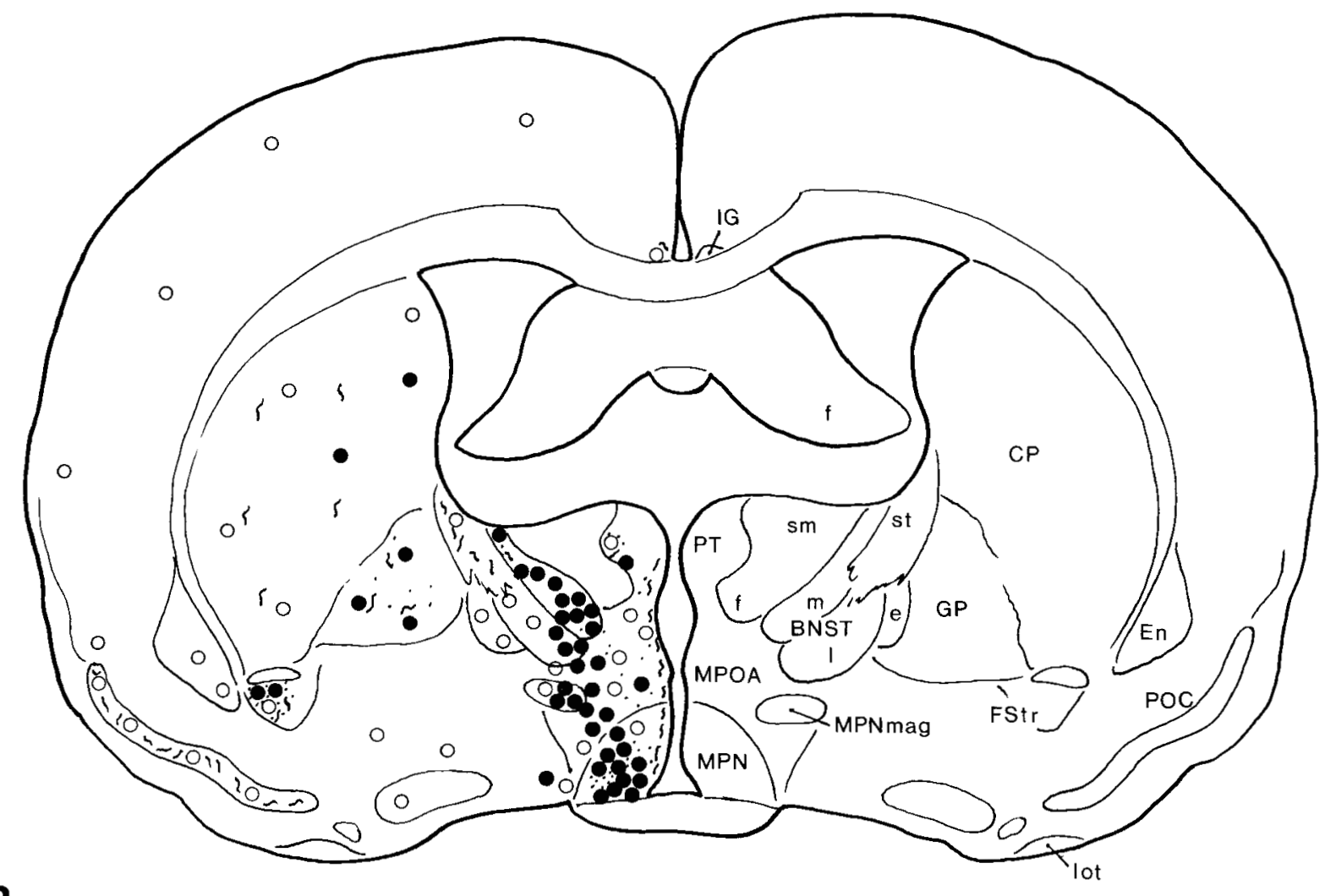

B 


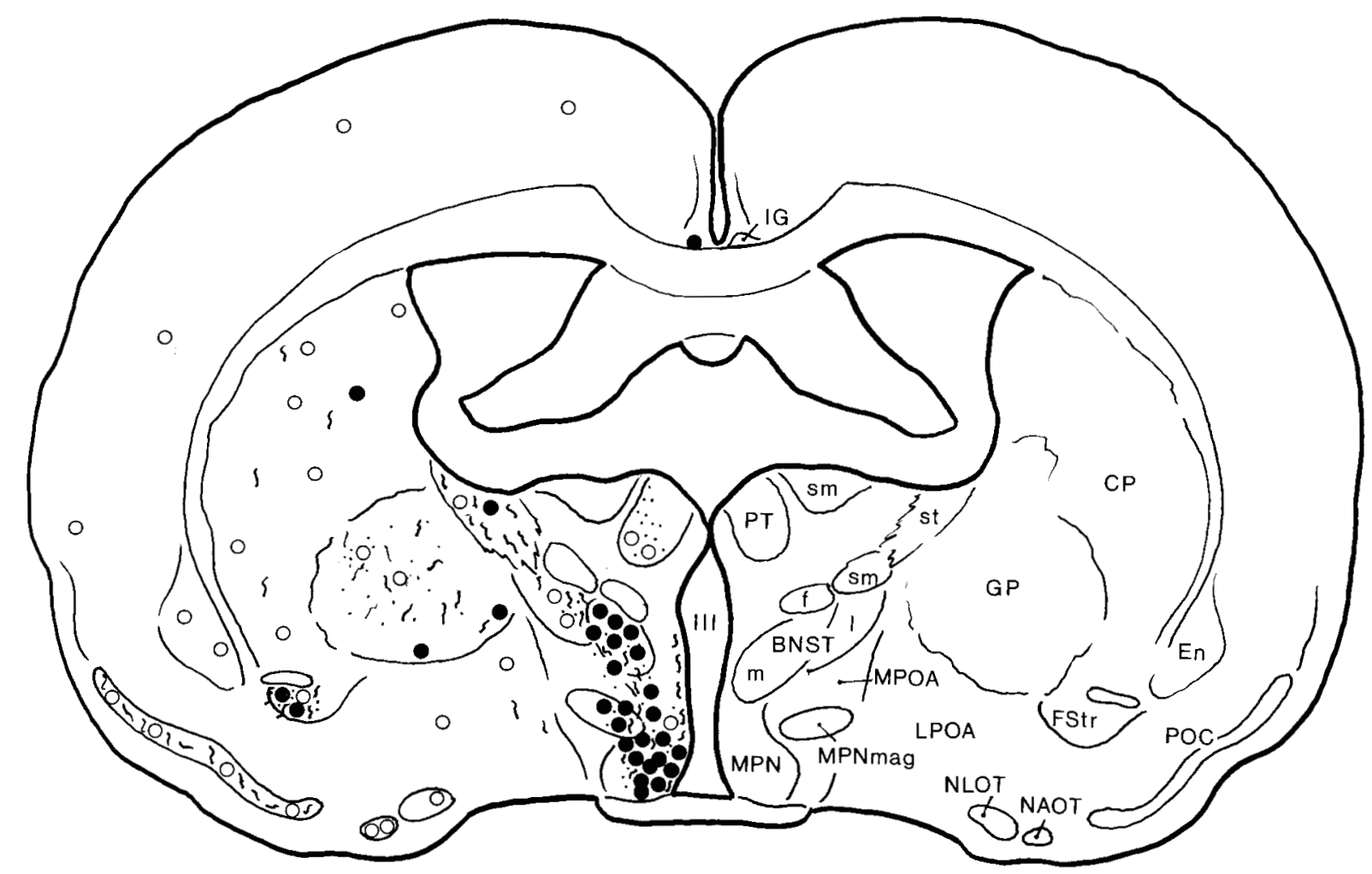

A

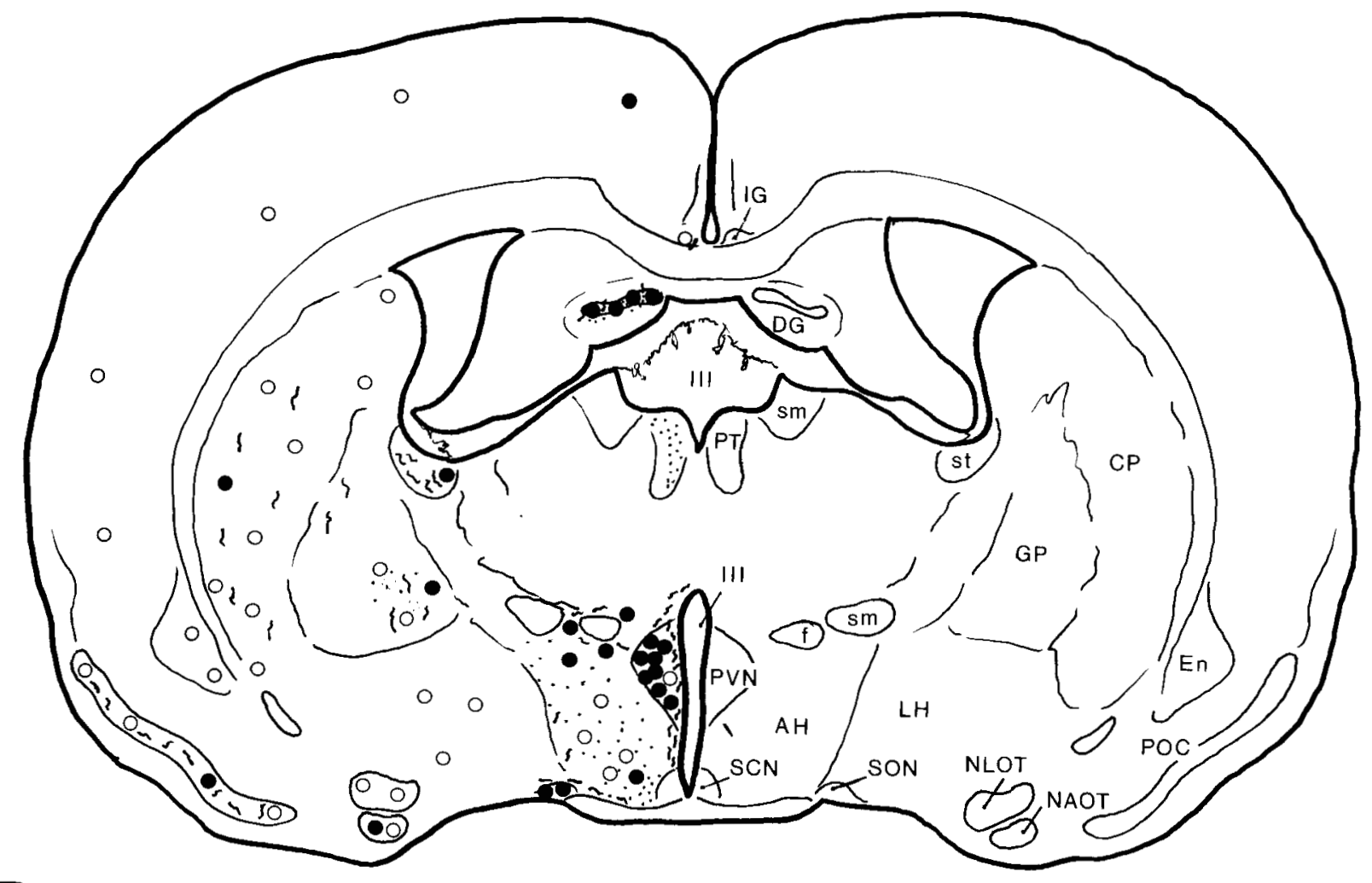

B 


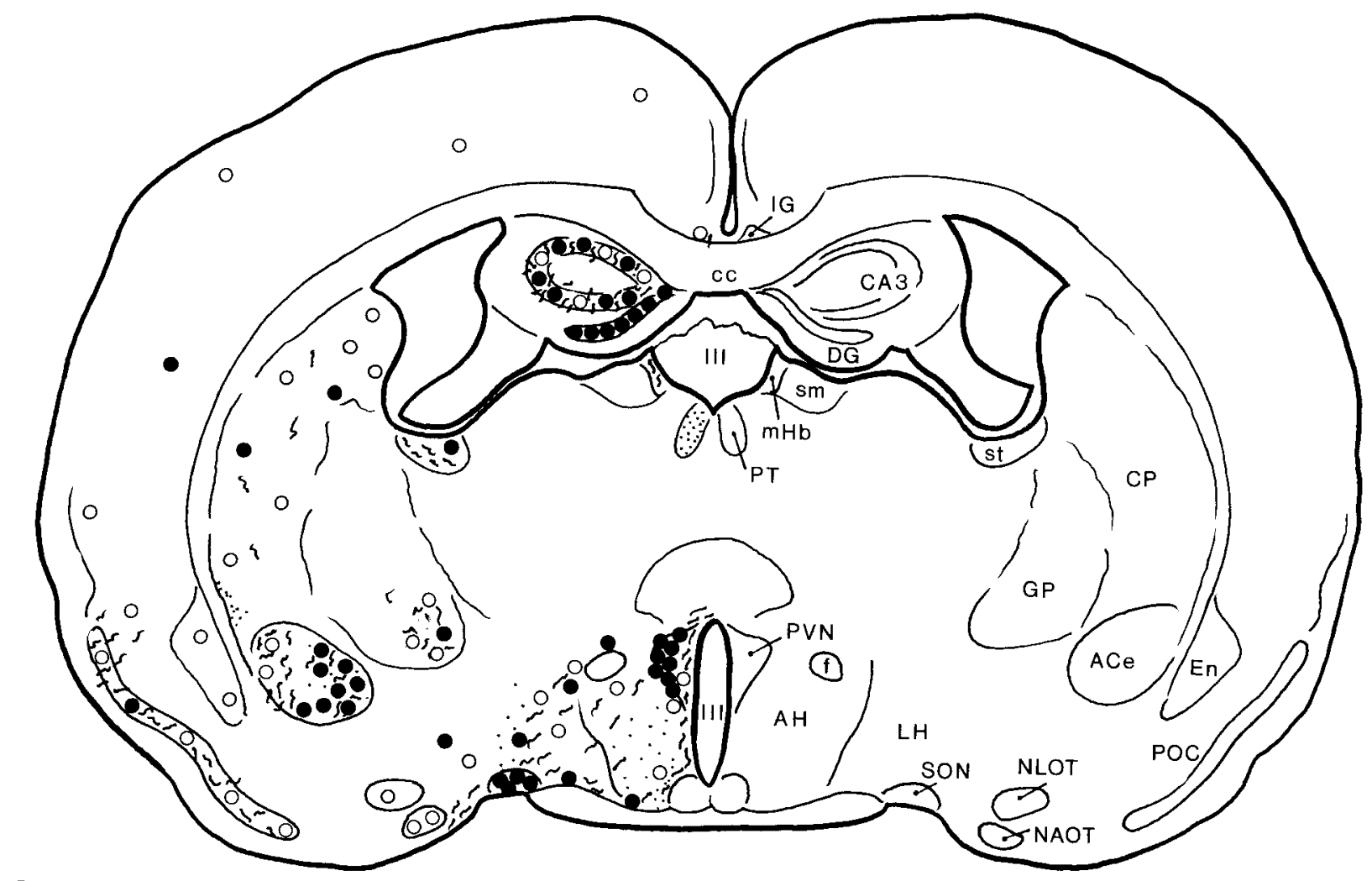

A

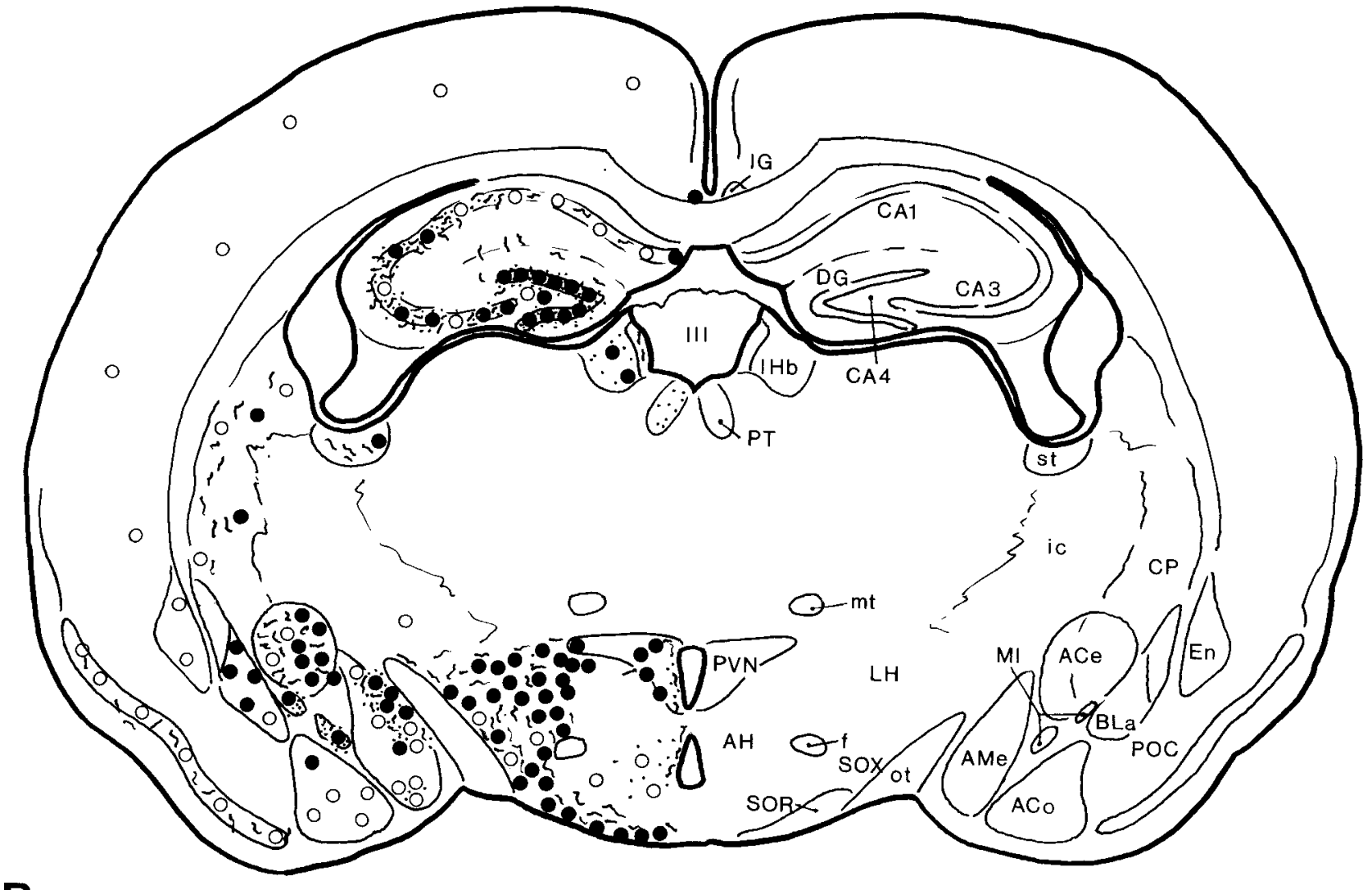

B

Figure 18 


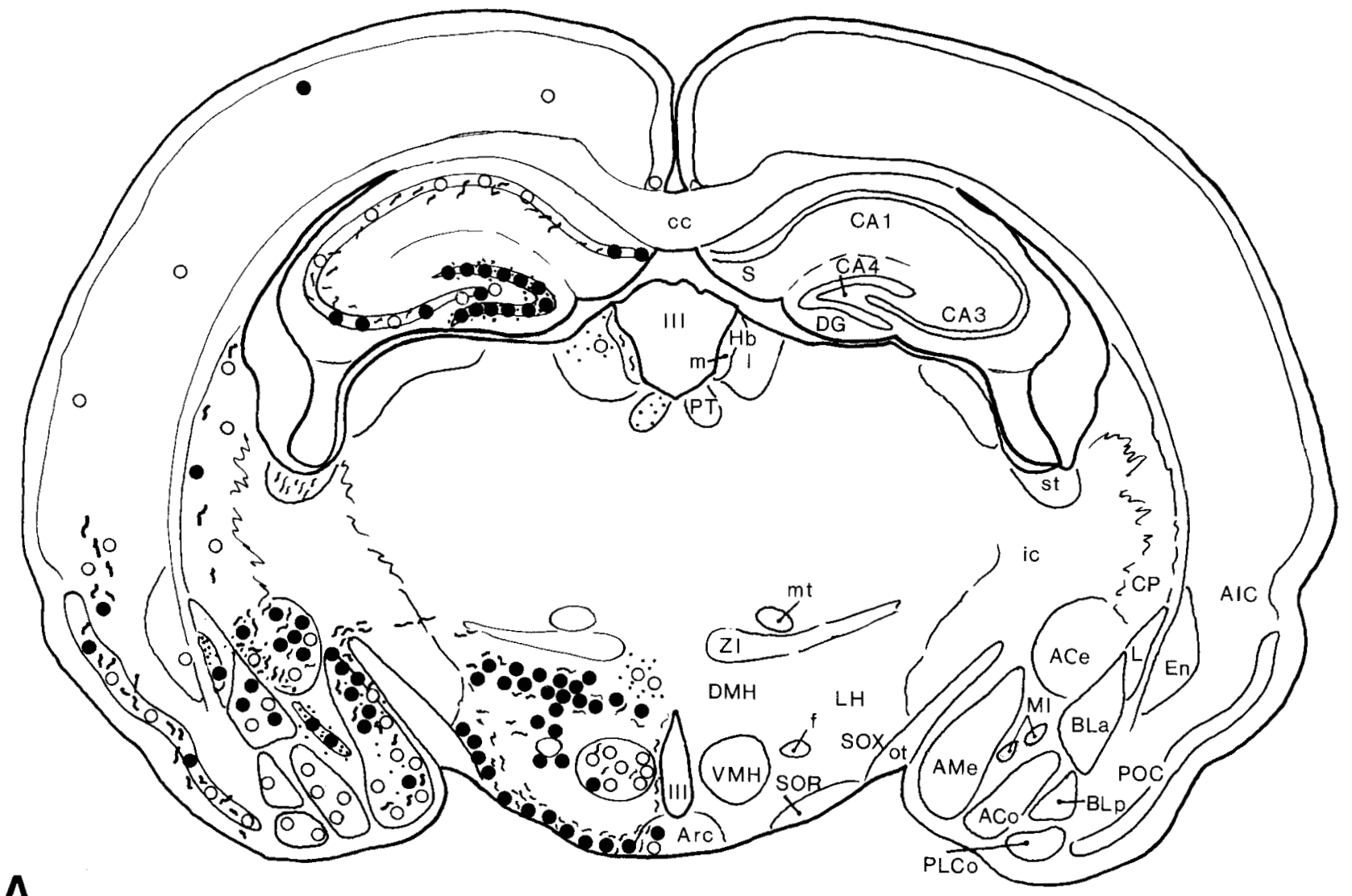

A

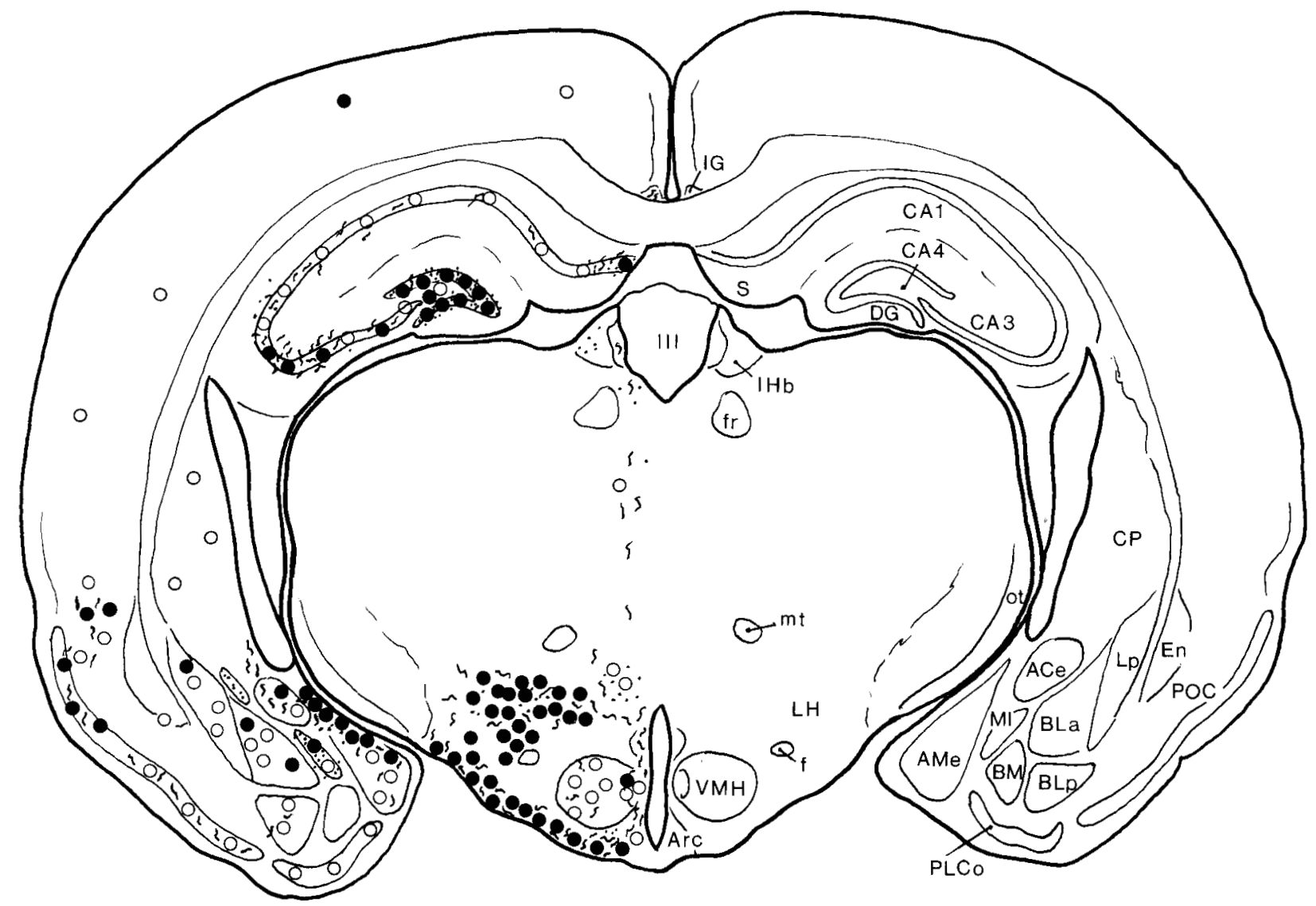

B 


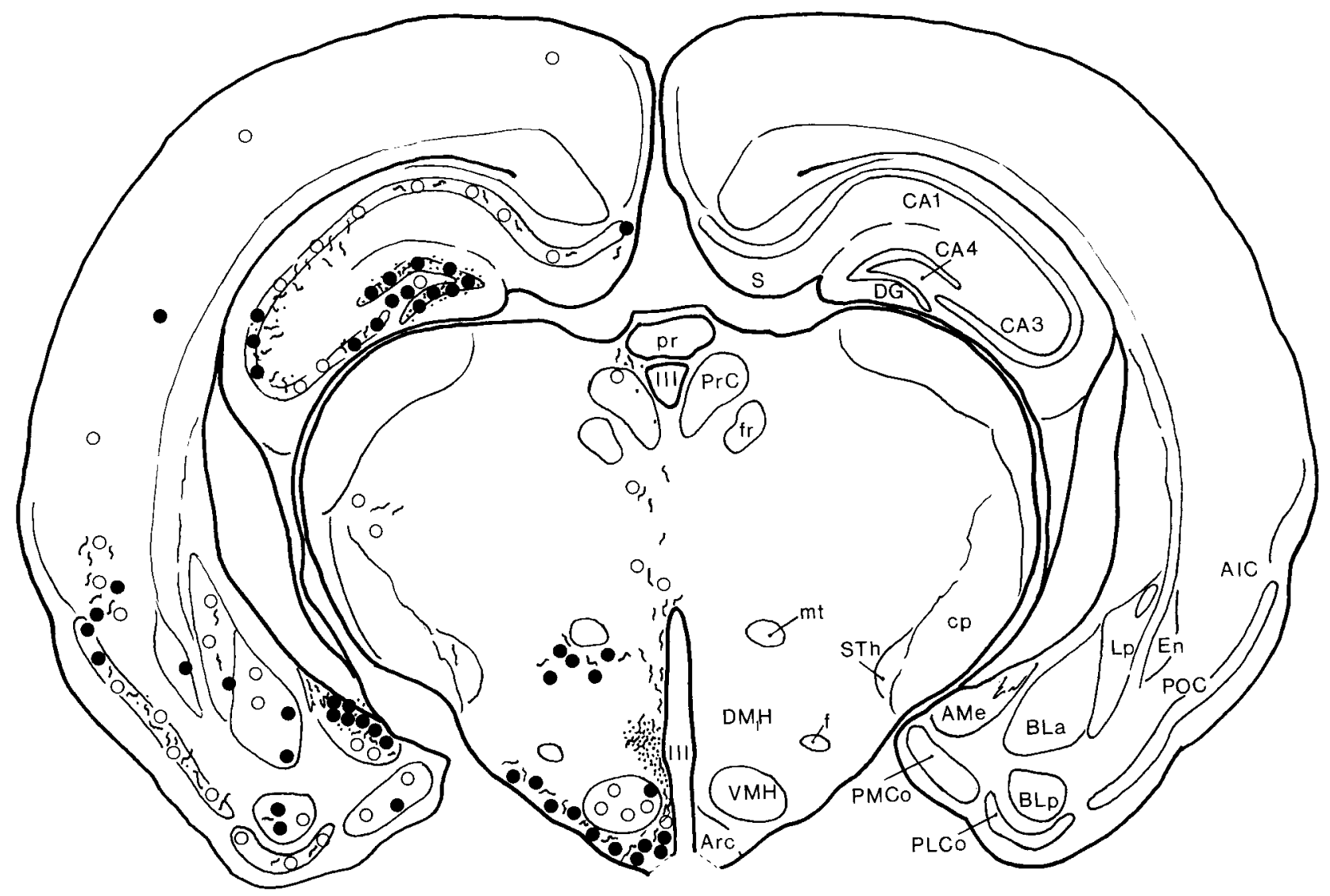

A

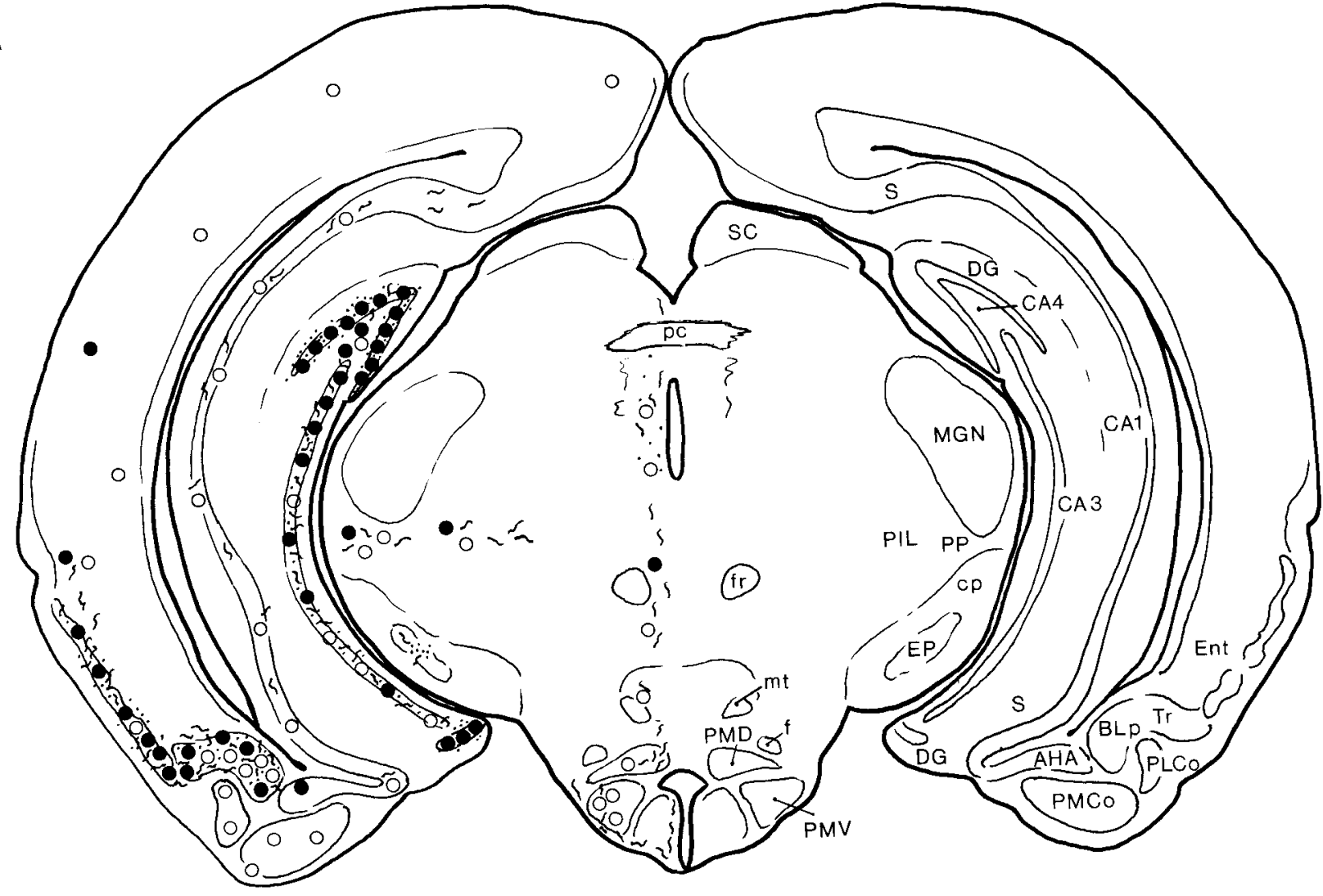

B 


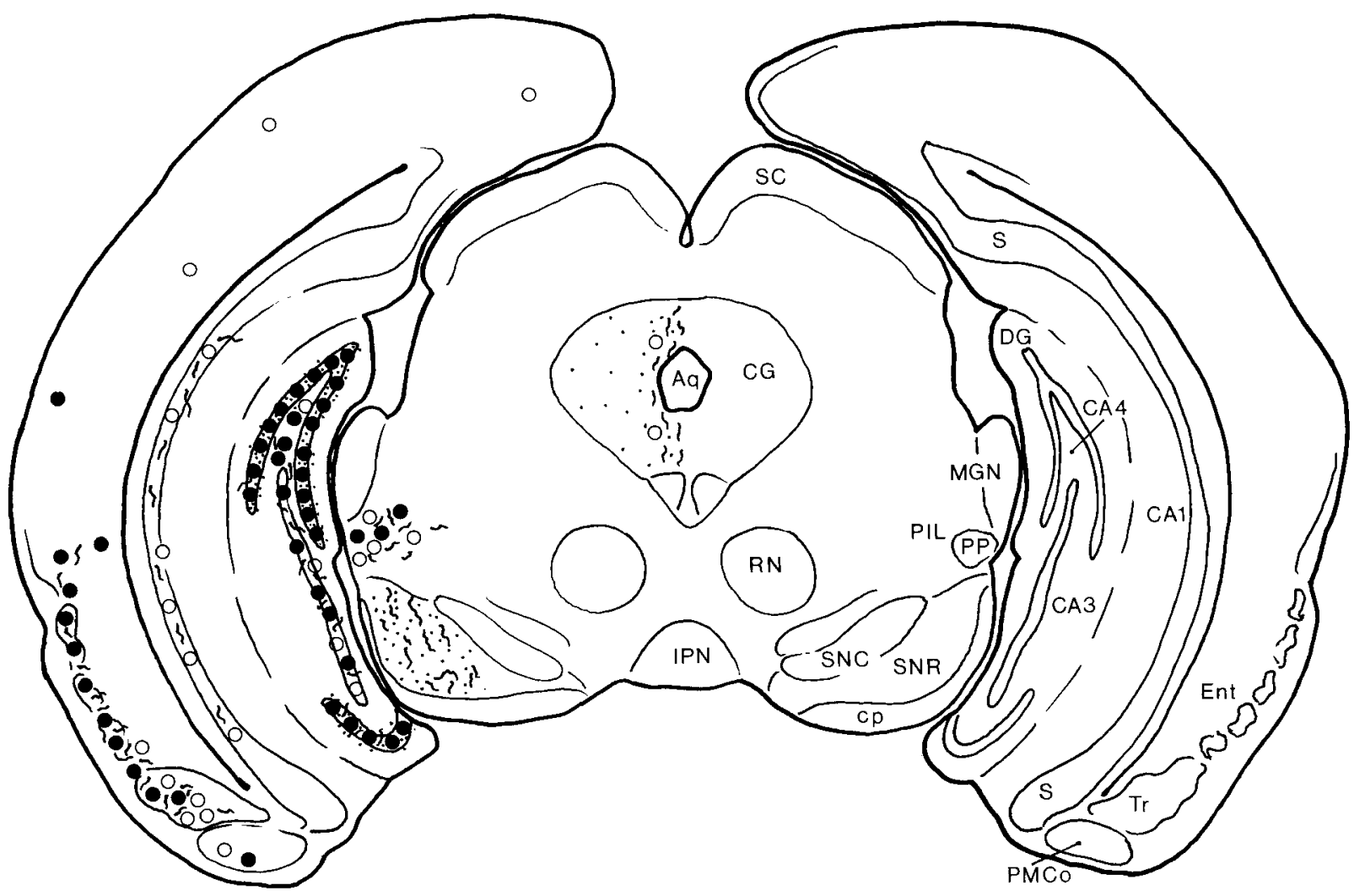

Figure 21

in the dorsomedial quadrant, lateral to the anterior continuation of the hippocampus (Fig. 13A). From this area to the caudal extent of accumbens, patches of fibers, terminals, and cells extended ventrally (Figs. 13A-14A). Caudally, staining increased with cells, fibers and terminals covering a large arc within the shell of the accumbens. The core of the accumbens contained much lighter cells and fibers with very few terminals (Figs. 13B, 14A). At levels where lateral septum staining was well developed, a continuous stream of prodynorphin-positive cells and fibers were observed from the lateral septum into the shell of accumbens. At the caudal end of accumbens, several single, darkly labeled cells and fibers surrounded the anterior limb of the anterior commissure, and terminals filled this area; this pattern continued caudally into the bed nucleus of the stria terminalis (Figs. 3A, 14B).

Dynorphin B staining was similar to that of C-peptide, but with heavier terminal clouds. Dynorphin A labeled many fewer cell bodies, but scattered fibers were consistently observed as well as a strong, diffuse terminal cloud over the whole nucleus.

In the nucleus accumbens of the rat, terminal fields were lighter rostrally and heavier caudally. Cells were numerous but confined to the medial part of rostral accumbens. A few light cells were observed capping the anterior limb of the anterior commissure, but immunolabeling was absent at the level of the bed nucleus of the stria terminalis.

Ventral to nucleus accumbens, in both rat and hamster light cell and terminal staining was observed in the cell bridges of the ventral striatum. Ventrolaterally, a cluster of darkly stained cells and terminals was found consistently in the fundus striati (Figs. 14B-17A). Dynorphin A and B antisera in the hamster labeled fewer cell bodies in fundus striati, but terminal staining in this area was similar.

In general, staining in the ofactory tubercle consisted of scattered weakly stained cells and terminals restricted to the islands of Calleja. Immunoreactive cells were found in all tubercle layers, mostly in layer II, with variations in the intensity of staining from animal to animal (Figs. 13A15A).

With dynorphin A and dynorphin B antisera, layer II showed pronounced fiber and terminal stain with scattered fibers observed in layer III as well. In rat tissue, dynorphin staining was restricted to clouds of terminal and fiber labeling in layers II and III of the tubercle, with only occasional labeled cell bodies observed in layer II.

Some of the islands of Calleja were distinctly outlined by terminal fields (Figs. 13B-15A). These islands were seen in both layers II and III of the olfactory tubercle, but primarily in the polymorph layer (III). Dense patches of terminals with pale-stained cells bordered the core, which was free of label. The majority of labeled cells were medium-sized, but occasional lightly stained granule cells were observed. The most distinct feature was the dense terminal stain bordering each island. Medially, at the interface between the intermediate lateral septum and nucleus accumbens, heavy terminals and scattered, dark cells were observed directly lateral to the insula Calleja magna complex (Fig. 14A). Although 
the total number of stained islands varied from hamster to hamster, the quality of stain remained consistent and the area lateral to the magna complex stained uniformly in all animals.

Dynorphin A and B antisera resulted in patterns similar to those of C-peptide, except that terminal fields surrounding the islands were more intensely stained with dynorphin $A$ and $B$ antisera. In the rat, light patches of terminals with a few scattered fibers were observed near, but not surrounding, a small number of islands. The intensity of this staining was much less than that observed in hamster.

In the rostral ventral pallidum moderate labeling of terminals and light cell staining predominated. At the level of the emergence of the bed nucleus of the stria terminalis (Fig. 14B), heavy ventral pallidal terminal and fiber staining with scattered single cells filled the area directly ventral to the anterior limb of the anterior commissure. This terminal and fiber staining created a "woolly fiber" appearance which disappeared at the level of the preoptic area.

Dynorphin A and dynorphin B staining in hamster and prodynorphin immunostaining in the rat gave similar staining patterns to that described above.

Basal telencephalon. Occasional immunolabeled cells and fibers were found in both the vertical and horizontal limbs of the nucleus of the diagonal band of Broca (Figs. 15B, 16A). Clusters of darkly stained cells and fibers also appeared in the lateral preoptic area between the horizontal limb and the ventral pallidum.

After staining for dynorphin B, the pattern in the nucleus of the diagonal band was very similar to that seen with $C$ peptide antiserum, but with far fewer cells stained. Labeling with dynorphin $\mathrm{A}$ antiserum was confined to fine terminal dust over both vertical and horizontal parts of the nucleus.

In the rat, occasional light cells were observed throughout the vertical and horizontal limbs, with lightly labeled fibers found in the horizontal limb more caudally.

The anterior part of the bed nucleus of the stria terminalis in the hamster contained numerous darkly stained cells, fibers, and terminals surrounding the crossing anterior commissure fibers (Figs. 3A, 14B-15B). Caudal to the body of the commissure, numerous darkly stained cells, fibers, and terminals filled the medial part of the nucleus (Figs. 9A, 16A-17A). From this area, which corresponds to the encapsulated bed nucleus of the stria terminalis of Simerly and Swanson ('86), the staining pattern continued caudally in the medial bed nucleus of the stria terminalis until the heavy cell/fiber cluster fused with the dorsally extending medial preoptic nucleus (Fig. 17A). This level corresponds to the preoptic bed nucleus of the stria terminalis. Scattered cells and fibers in the lateral part of the bed nucleus of the stria terminalis were much less intense and numerous than those seen in the medial part.

The distribution of stained cells and fibers with dynorphin B antiserum was similar to that of C-peptide antiserum. Fewer cells and fibers stained with dynorphin $B$ and fibers were more heavily immunolabeled than cells. Dynorphin A antiserum labeled the bed nucleus with a consistent pattern of scattered cells, terminals, and a few fibers with varicosities over the same parts described above.

In the rat, staining in the bed nucleus of the stria terminalis consisted of occasional light cells and scattered fibers in its medial, lateral, and preoptic parts posteriorly. Anteriorly there were distinct cells stained in the medial part and scattered fibers in the ventral part. However, at all levels in the rat brain the staining in this nucleus was, quantitatively and qualitatively, significantly less than that seen in the hamster (Fig. 9).

Rostral preoptic area staining in the hamster was generally light, but caudal to the body of the anterior commissure the staining increased significantly. In the rostral half of the preoptic area a few lightly stained cells were observed in the anterodorsal preoptic nucleus (Fig. 15A). This labeling increased in intensity at the body of the anterior commissure. Diffuse fibers with numerous varicosities and some terminal staining were observed in the median preoptic nucleus, both dorsal and ventral to the body of the anterior commissure (Fig. 15A,B). The majority of prodynorphin immunoreactive cells in the rostral preoptic area were confined to the medial preoptic nucleus.

In the caudal preoptic area the most prominent group of darkly stained cells was the ventromedial part of the medial preoptic nucleus (Figs. 8A, 16A). This cell group spread dorsal and lateral to meet the preoptic bed nucleus of the stria terminalis (Fig. 17A). Laterally cell staining in the magnocellular medial preoptic nucleus, described by Maragos et al. ('89), was very dark (Figs. 16B, 17A), but labeled cells were less numerous than in the medial preoptic nucleus proper. Fiber staining in the medial preoptic area was very dark and terminal stain was light, with the exception of the caudal ventromedial part of the medial preoptic nucleus where terminal staining was heavy (Figs. 16B, 17A). Fiber staining in the preoptic periventricular nucleus was strong and this fiber system extended into the hypothalamus (see description below).

At the level of the transition from the medial preoptic area to the anterior hypothalamus very few lightly labeled cells, and patches of labeled fibers and terminals were observed (Figs. 2A, 17B). Large, darkly stained cells were also sparsely distributed in the lateral preoptic area.

In the preoptic area, dynorphin B and C-peptide immunostaining was virtually identical at all levels. Dynorphin B labeled somewhat fewer cells but equal numbers of fibers and terminals. In contrast dynorphin $A$ antiserum produced much less cell staining in this area, with labeled neurons confined to the medial preoptic nucleus caudally, and few in number.

Prodynorphin staining in the rat preoptic area was strikingly different from the hamster (Fig. 8A,B), with only two clusters of moderately stained cells observed, one in the medial preoptic nucleus ventrally (small cells in a tight cluster) and the other just ventral to the fornix in the caudal dorsal medial preoptic area. Fiber stain was very sparse, with scattered, lightly stained fibers found mostly in the caudal part of the medial preoptic nucleus.

Hypothalamus. Both the preoptic part of the periventricular nucleus and its continuation into the hypothalamic periventricular nucleus contained a heavily stained fiber plexus with prominent terminal labeling (Figs. 15B$20 \mathrm{~A}$ ). The fiber plexus was confined to the dorsal two-thirds of the nucleus, while terminal staining was uniformly dense throughout. This periventricular staining pattern decreased in intensity caudal to the ventromedial nucleus.

The supraoptic nucleus was filled with numerous, intensely labeled cells of varying sizes, with dark fibers and moderately dense terminals throughout its length (Figs. 6C, $17 \mathrm{~B}, 18 \mathrm{~A})$. The heavily stained fibers of the supraoptic 
nucleus could be followed as they flowed dorsally and medially around the optic tracts and caudally toward the arcuate nucleus and median eminence.

In the retrochiasmatic supraoptic nucleus the intense cell staining was like that of the supraoptic nucleus. These retrochiasmatic cells appeared to send fibers in a more direct route toward the arcuate nucleus (Figs. 18B-20A). Fiber and terminal staining was lighter in intensity than that of the supraoptic nucleus. Numerous fibers and terminals were also observed medial to the retrochiasmatic supraoptic nucleus, in an area ventral to the rostral part of the ventromedial hypothalamus (Fig. 19B).

Large, darkly labeled cells and fibers were scattered throughout the area of the supraoptic decussation, with a few patches of terminals. The labeled cells in this area were less numerous than in the supraoptic nucleus. Prodynorphin fibers from this area could be seen following the same trajectory as those of the supraoptic nucleus (i.e., medially and caudally toward the medial eminence).

In the paraventricular nucleus a moderate number of lightly stained cells with light terminal label were scattered in the anterior, medial, and ventral parvicellular parts. In contrast, dark cells and fibers were found in the magnocellular paraventricular nucleus, with very large, thick fibers extending laterally toward the lateral hypothalamus and retrochiasmatic supraoptic nucleus (Figs. 6A, 18A,B).

Light terminal staining bordered the rostral suprachiasmatic nucleus laterally and dorsally but there was no staining within the nucleus (Figs. 17B, 18A).

The rostral anterior hypothalamic area contained weakly stained, single, scattered cells and fibers. Fiber and terminal staining increased ventrocaudally and a few cells were noted (Figs. 17B-18B). This staining pattern continued to the level of the retrochiasmatic supraoptic nucleus.

The mediobasal hypothalamus contained heavy immunolabeling. In the ventral part of the arcuate nucleus (Figs. 19A-20A) a moderate terminal and fiber plexus surrounded lightly labeled cells and extended ventrally into the median eminence. Neurons throughout the ventromedial nucleus of the hypothalamus were more numerous, but lightly stained, except for a small oval-shaped subdivision of the nucleus adjacent to the third ventricle, which contained a concentration of moderately labeled cells (Fig. 19B). Fiber and terminal staining in the ventromedial nucleus was most distinct in its dorsomedial part, throughout its rostrocaudal extent.

At the most caudal level of the ventromedial nucleus, the periventricular zone between the ventromedial and dorsomedial nuclei contained a few darkly labelled cells (not shown on figure) and heavy fiber and terminal staining, which extended laterally beyond the periventricular nucleus itself (Fig. 20A). Light terminal and cell stain in the dorsomedial hypothalamic nucleus was continuous laterally with the striking, heavily labeled cells of the lateral hypothalamus (Fig. 19A).

At the most rostral extent of the lateral hypothalamic area, large and very dark multipolar cells with long dark fibers (Fig. 18A) extended from the paraventricular nucleus through the lateral hypothalamus to the retrochiasmatic supraoptic nucleus (Fig. 18B). The number of labeled cells increased caudally, filling the lateral hypothalamus and extending medially into the dorsomedial area (Figs. 7B, 18A19B). The most intense staining of individual cells was at midrostral lateral hypothalamus levels, where labeled neu- rons were found primarily in the dorsal one-third, dorsal to the perifornical area. The perifornical area itself contained lightly stained, scattered cells, fibers, and terminals surrounding the fornix (Figs. 18B, 19A).

Scattered cells with some fibers were found in the posterior hypothalamic area, directly dorsal to the third ventricle, as well as in a small area over the ventricle's dorsal tip (Figs. 19A-20A). These scattered cells in were seen throughout the extent of this area.

A few lightly stained cells, fibers, and terminals were observed in the dorsal and ventral premammillary nuclei (Fig. 20B). More darkly stained cells were located just ventral to the ventral premammillary nucleus. A few single, dark, scattered cells in the supramammillary nucleus were very distinctly labeled (Fig. 20B).

Dynorphin B immunolabeling in the hypothalamus was very similar to C-peptide with two exceptions; the arcuate nucleus contained more dynorphin B-immunolabeled cells than C-peptide cells, and the ventromedial nucleus had fewer immunolabeled cells but heavier fiber labeling medially. Dynorphin A antiserum resulted in a pattern similar to C-peptide but produced considerably less cell staining in the anterior hypothalamus, paraventricular nucleus, and dorsomedial nucleus. However, dynorphin A cell labeling in the lateral hypothalamus and arcuate nucleus was distinctly more intense than that of C-peptide. The lateral hypothalamus (Fig. 1D-F) and arcuate nucleus were rare examples in the hamster where both dynorphin $B$ and $A$ cell staining was heavier than that observed with C-peptide.

There were a few minor differences between rat and hamster immunolabeling in the hypothalamus. In the rat paraventricular nucleus, cell staining was confined mostly to magnocellular cells laterally, while in hamster there were occasional parvicellular cells labeled. However, in general, the paraventricular nuclei staining patterns were similar. Also, the very dark fiber and terminal plexus observed between ventromedial and dorsomedial hypothalamic areas in the hamster was not as distinct in the rat. All other nuclei were similarly labeled in rat and hamster (Figs. 6, 7).

Amygdala. The entire length of the stria terminalis contained scattered fibers with occasional distinctly stained cells intermingled with the fibers (Figs. 16A-19A). Dynorphin $B$ immunolabeling in the stria terminalis was identical to the C-peptide pattern. Dynorphin A antiserum labeled fibers lightly but no cell staining was observed. In the rat there were no immunolabeled cells, and fiber staining observed was lighter than that produced with any prodynorphin antiserum in the hamster.

The nucleus of the accessory olfactory tract contained a small cluster of lightly stained cells, which stretched caudally until the nucleus disappeared at the anterior border of the medial nucleus of the amygdala (Figs. 17A-18A). A few cells were labeled in the nucleus of the lateral olfactory tract (Figs. 17A-18A).

The massa intercalata contained scattered, darkly labeled cells and clusters of heavily labeled terminals. This terminal staining was some of the heaviest in the hamster forebrain and because of it the massa intercalata stood out distinctly to the most caudal level of the amygdala (Figs. 18B-19B).

At rostral levels the medial division of the central nucleus contained large, dark, prodynorphin cells, whereas the lateral subdivision contained scattered dark fibers and lightly 
stained cells (Fig. 18A,B). Caudally, heavily labeled cells and numerous dark fibers with varicosities were found throughout the central nucleus (Fig. 19B).

In the medial nucleus, the anterior dorsal subdivision contained single, scattered, lightly stained cells. Scattered fiber and terminal stain was very light. In the mid to caudal parts of the nucleus, stained cells increased in number and intensity, filling the posterodorsal subdivision (Figs. 1A, 8C, 18B-20A).

Rostrally, the ventral anterior cortical nucleus was labeled with scattered, distinctly stained cells (Figs. 18B, 19A) and the dorsolateral part contained numerous small, lightly labeled cells. Caudally, there were few immunolabeled cells. Scattered large, light cells were observed in the posterolateral cortical nucleus (Figs. 19A-20B). The posteromedial cortical nucleus contained medium-sized, lightly stained cells (Figs. 20A-21).

The anterior division of the lateral nucleus showed no staining, whereas the rostral extent of the posterior division of the lateral nucleus contained small to medium-sized lightly stained cells. Caudally, the posterior division contained numerous dark cells laterally, along the external capsule, and lighter-staining cells medially. At all levels, fiber staining in the lateral nucleus was very sparse (Figs. 19B, 20A).

The rostral anterior basolateral nucleus contained large and medium-sized, moderately stained cells, with very little fiber and terminal staining. This nucleus was bounded by the intercalated nuclei on its medial and lateral aspects, and ventromedially by the basomedial nucleus, which was devoid of staining (Figs. 19A-20A). Caudally, dark, large and medium-size multipolar neurons were scattered throughout the nucleus (Fig. 19B). The most caudal tip of the anterior basolateral nucleus was free of immunolabeled cells.

The posterior basolateral nucleus contained occasional lightly stained, scattered, single cells rostrally (Fig. 19B) and numerous, medium-sized, darkly stained neurons with light fiber staining caudally. At its most caudal level, this staining was continuous with strong cell staining in the transitional area of Haug (Figs. 20B, 21).

Dynorphin $\mathrm{B}$ antiserum produced a staining pattern in the amygdala of the hamster that contained fewer dynorphin B-labeled cells in every nucleus described above. However, fiber and terminal stain was approximately equal to that for C-peptide. Exceptions were the massa intercalata and the posterior division of the lateral amygdaloid nucleus, which stained with equal intensity with both antisera.

Staining for dynorphin $\mathrm{A}$ in the amygdala was limited to strong massa intercalata label similar to C-peptide and dynorphin B, cell and fiber stain in the medial and central nuclei which was less in intensity than $\mathrm{C}$-peptide and dynorphin B, and occasional cells in the posterior lateral nucleus. The remainder of the amygdaloid nuclei contained only distinctly labeled dynorphin A fibers and terminals.

In the rat, the central nucleus contained immunolabeled fibers and cells, the cells concentrated laterally and the fibers medially. This pattern was the reverse of that in the rostral hamster central nucleus, which contained more cells in the medial subdivision than in the lateral, but was similar caudally. Other staining in the rat amygdala was confined to occasional cells, light terminal dust, or light scattered fibers in several nuclei, none of which were equal to the hamster in intensity. This region of the brain, without doubt, presented the greatest diversity when comparing species (Fig. 8C,D) and when comparing immunostaining with the three different prodynorphin antisera in the hamster (Fig. 1A-C).

Thalamus and rostral midbrain. Unlike the parataenial nucleus in the rat, this nucleus in the hamster continues caudally to the level of the nucleus parafascicularis (Newman and Winans, '80a,b). Rostrally, several moderately stained cells were observed (Fig. 16A,B), and caudally, parataenial stain was confined to scattered fibers and distinct terminals (Figs. 2B, 17A-19A). Dynorphin B antiserum resulted in an identical pattern in the parataenial nucleus to that of $\mathrm{C}$-peptide, as did dynorphin $\mathrm{A}$, with the exception that no dynorphin A cell bodies were observed. Fibers were not only observed in the parataenial nucleus in rat, but they were also observed in the periventricular nucleus. In general, immunostaining in the rat parataenial and periventricular nuclei was confined to fibers, while in the hamster terminals were more distinct.

Though prodynorphin staining was virtually absent in the remainder of the thalamus, some structures in the caudal dorsal thalamus and adjacent rostral midbrain showed immunoreactivity. A cluster of cells and fibers were observed rostral to and in the peripeduncular nucleus (Figs. 20A-21), some fibers extending medially into the posterior intralaminar nucleus. Scattered, large, lightly stained cells and moderately stained fibers were located medial and ventral to the parafascicular nucleus, extending into the posterior hypothalamus (Figs. 19B-20B). Medially, lightly stained cells and distinct fibers and terminals extended caudally into the central gray (Figs. 20B, 21). Finally, immunolabeled fibers in the medial habenula and terminals in the lateral habenula were observed. Occasionally, a few light cells were present in the lateral habenula (Figs. 18A-19B). At the level of the habenular commissure, scattered light cells and terminals were labeled in the precommissural nucleus (Fig. 20B).

In the structures just described, dynorphin B and A labeling was similar to and uncharacteristically more intense than C-peptide labeling in many areas. Dynorphin B cell staining was darker and more numerous in the peripeduncular nucleus as was cell, fiber, and terminal staining ventromedial to the posterior intralaminar nucleus. Dynorphin B fibers in the medial habenula were similar to those observed with C-peptide while lateral habenula had occasional scattered immunolabeled cells and heavier terminal labeling. The precommissural nucleus and central gray both contained several scattered, darkly labeled cells. Dynorphin A fiber and terminal stain in the peripeduncular nucleus, medial habenula, lateral habenula, precommissural nucleus, and ventromedial to the posterior intralaminar nucleus was consistently stronger than that observed with C-peptide. Dynorphin A cells were also prominent in the peripeduncular nucleus, central gray, and precommissural nucleus. In general, cell staining in the above structures was strongest with dynorphin B, and fiber and terminal stain was strongest with dynorphin $\mathrm{A}$.

In the rat, fiber and terminal labeling in the precommissural nucleus and lateral habenula was light. The central gray contained light fibers and terminals with large, dark, scattered cells. Immunolabeled cells were observed in the precommissural nucleus. Though $\mathrm{C}$-peptide staining was not identical in rat and hamster thalamus and adjacent structures, this area was similar in both species in that pro- 
dynorphin staining was absent from most thalamic structures and, when present, was not as dramatic as the immunostaining observed in other forebrain areas.

\section{DISCUSSION Technical considerations}

Immunostaining in brains fixed with parabenzoquinone combined with $2 \%$ paraformaldehyde demonstrated clear cell morphology and better fiber and terminal differentiation on a more consistent basis than $4 \%$ paraformaldehydefixed brains. However, no differences in staining patterns were generated by the two fixatives. There are several possible explanations for the superiority of parabenzoquinone. This compound is known to react with protein amino groups to form a disubstituted quinone (Means and Feeney, '71) which can further react with either free amino groups or with sulfhydryl groups in close proximity, creating crosslinking of proteins and enhancing fixation of tissue (Morrison et al., '69). In addition parabenzoquinone has been recommended for vapour-and liquid-phase fixation of tissues for immunohistochemical procedures (Pearse and Polak, '74, '75) because it blocks the proteolytic activity of enzymes reacting at Lys-Arg or Lys-Lys bonds. It is possible that the excellent parabenzoquinone preservation of dynorphin peptide antigens results from optimal peptide fixation and/or from rendering these antigens impervious to proteolytic digestion.

The PAP procedure, with Permount used as a mounting medium, produced superior results to those of the immunofluorescence procedure when sections were coverslipped with DPX. However, when FITC-labeled sections were coverslipped with a glycerol-based mounting medium containing phenylenediamine (Platt and Michael, '83), FITC fading was virtually eliminated, and the intensity of the fluorescent staining was enhanced. This produced immunofluorescence patterns equal in intensity and morphology to our PAPstained material, allowing us to compare our results directly with those of other investigators who have reported prodynorphin localization using indirect immunofluorescence techniques. In the rat, the PAP and immunofluorescence techniques produced C-peptide patterns identical to one another and consistent with patterns reported elsewhere for prodynorphin in the rat brain (Khachaturian et al., '85; Fallon and Leslie, '86).

\section{Hamster and rat: species differences}

The C-peptide, dynorphin B, and dynorphin A antisera produced identical staining patterns in our rat material and this distribution was consistent with prodynorphin staining reported by other investigators in the rat (Nakao et al., ' 81 , '83b; Khachaturian et al., '82, '85; Watson et al., '82a,b, '83; Palkovits et al., '83; Weber and Barchas, '83; Zamir et al., '83; Akil et al., '84; Smialowski et al., '85; Fallon and Leslie, '86). Our observations in the hamster are also in good agreement with the general distribution of dynorphin described in the rat. However, there were several areas of difference between the species that require further discussion.

Using the C-peptide antiserum we consistently demonstrated strong cell, fiber, and terminal staining in the major nuclei of the chemosensory pathways that control male hamster sexual behavior - the medial preoptic area, medial part of the bed nucleus of the stria terminalis, and medial nucleus of the amygdala. However, in simultaneously processed rat tissue, the intensity of staining and quantity of stained elements were consistently lower or absent in these same areas (Figs. 8, 9).

In general, species differences were significant in the amygdala. As mentioned above, prominent cell and fiber staining was observed throughout the medial nucleus in the hamster, whereas only an occasional labeled cell was observed in the rat. Although the intensity of stained elements in the central nucleus of the rat and hamster was similar, there was differential distribution of immunostaining within the nucleus. In the rat, immunolabeled cells were mostly confined to the lateral subdivision, while fibers were observed laterally and medially, which is in agreement with the report of by Fallon and Leslie ('86). In the hamster, cells were confined to the medial division rostrally, with heaviest fiber staining in the lateral subdivision; cells and fibers were located in both the medial and lateral parts caudally (Figs. 18A-19B). In all remaining amygdaloid nuclei of the hamster where immunostaining was described, only occasional scattered light cells and fibers were observed in the rat.

Species differences were also distinct in the hippocampal formation. Dymorphin immunoreactivity in the hippocampal formation of the rat has been reported in several studies (McGinty et al., '83; Fallon and Leslie, '86; McLean et al., '87). In these studies, pyramidal cell staining in CA1, CA2, and CA 3 of Ammon's horn as well as granule cell and mossy fiber staining of the dentate gyrus have been reported. The cell staining observed in the hamster CA4 region with the $\mathrm{C}$-peptide antibody has not been reported previously (Figs. $4,10 \mathrm{~A}$ ). Also, the presence of intense immunostaining in the granule cell layer of the dentate gyrus in the hamster is in marked contrast to that observed in the rat. The intensity of immunolabeling in CA3 of the hamster is also greater than that in the rat.

A less striking but consistent difference between hamster and rat brains was seen in the substantia nigra. Both in our rat material and in other studies of the rat, cell staining has been observed (Fallon and Leslie, '86). In the hamster we did not observe cell staining in any part of the substantia nigra with C-peptide, dynorphin A, or dynorphin B antisera, though these same antisera revealed light cell staining in our rat tissue. In contrast, distinct fiber and terminal stains in pars reticulata of rat and hamster were equivalent.

Distinct cell and fiber staining has also been reported in the striatum and globus pallidus in the rat (Watson et al., '82a; Weber and Barchas, '83; Fallon and Leslie, '86). In the hamster this staining, though present, was consistently less, both qualitatively and quantitatively.

In the lateral septum of the rat Fallon and Leslie ('86) reported immunoreactive fibers encircling cells, but no cells labeled for dynorphin B. In hamster material we observed numerous dark cells stained in dorsal and ventral lateral septum. This labeling was strongest with C-peptide antiserum (Fig. 5) but also quite pronounced with dynorphin B. In contrast, the dynorphin A antiserum produced a pattern similar to that described in the rat, but with less fiber staining than reported by Fallon and Leslie ('86).

Although several brain areas provided consistent differences between rat and hamster after simultaneous immunohistochemical processing of sections, there were also several areas where staining patterns were similar (Figs. 6, 7). Taken together, these results suggest that species differences exist in the quantity of various prodynorphin products within cells and/or fibers in select areas of the brain. 


\section{Dynorphin A, dynorphin B, and C-peptide antisera: labeling variations in the hamster brain}

In the rat we observed no differential staining when using the dynorphin A, dynorphin B, or C-peptide antiserum. In the hamster, however, immunostaining of specific cell groups from the same brain with antisera against dynorphin A [1-17] (Terenius), dynorphin B [1-13] (Terenius and Watson) and C-peptide (Watson) yielded differential staining.

In the medial preoptic area, bed nucleus of the stria terminalis and medial nucleus of the amygdala, dynorphin B antiserum immunolabeled fewer cell bodies and fibers than C-peptide, with a further appreciable drop in number of stained elements when using dynorphin A antiserum (Fig. 1A-C). The dynorphin A antiserum, however, still produced quantitatively more staining in these areas in hamster than in rat brain tissue.

CA4 cell staining in the hippocampal formation with $\mathrm{C}$ peptide antiserum was not observed in the hamster with either the dynorphin A or dynorphin B antiserum. In the dentate gyrus dynorphin $B$ antiserum produced less granule cell layer immunoreactivity than that observed with C-peptide. However, granule cell layer staining was still much stronger than that observed in the rat. The dynorphin $A$ immunostaining pattern, however, was similar to the pattern observed in the rat and different from that obtained with the C-peptide or dynorphin B antiserum in the hamster.

A differential pattern of immunolabeling was also observed in the lateral septum. In this structure dynorphin B antiserum labeled fewer cells than C-peptide but still stained a larger number of cells than in the rat. The dynorphin A antiserum immunolabeled only occasional cell bodies but numerous fibers in a pattern similar to what was observed in the rat tissue.

In contrast to the amygdala, hippocampal formation, and preoptic area, several areas of the diencephalon and midbrain were more heavily labeled with the dynorphin $A$ and $B$ antisera than with the C-peptide antiserum. In the lateral hypothalamus dynorphin $\mathbf{A}$ and $\mathbf{B}$ antisera labeled a greater number of cell bodies and fibers than the C-peptide antiserum (Fig. 1D-F). In the peripeduncular nucleus, medial and lateral habenula, central gray, precommissural nucleus, and arcuate nucleus of the hypothalamus more immunolabeled cells and fibers were observed with the dynorphin A and $B$ antisera.

One possible interpretation of differential immunostaining within the hamster brain is that the C-peptide antiserum has greater affinity for the $\mathrm{C}$-peptide sequence than the dynorphin $B$ antiserum does for its peptide sequence. The dynorphin B antiserum, in turn, may have greater affinity for its antigenic site than the dynorphin $A$ antiserum for its peptide. If this is indeed the case, then all prodynorphin antisera used in this study have equal affinity against their respective peptides in the rat brain, but not in the hamster brain.

A second possibility is that the variation in staining resulted from differential effects of the perfusates on the three peptides within the hamster brain. It is possible that the perfusion techniques used in this study enhanced preservation of some peptide sequences more than others or preferentially preserved some antibody recognition sites. If this were the case, then differential staining patterns would be a result of accessibility of antigenic sites for antisera recognition, rather than presence or absence of the peptides.

A third possibility is that in some areas of the hamster brain there may be a differential processing of the prodynorphin precursor such that dynorphin $A$ and dynorphin $B$ peptides are produced in reduced amounts or in immunohistochemically undetectable amounts, whereas the C-terminus product (leumorphin) is produced in high quantities in these same neurons. Evidence for selective processing of prodynorphin products has been reported in rat brain (Seizinger et al., '84a, b; Dores et al., '85).

The very distinct $C$-peptide immunoreactivity observed in the hamster but not observed with the other dynorphin antisera may be a reflection of any of the three mechanisms mentioned above. However, some areas of the hamster brain showed strong C-peptide immunolabeling where dynorphin $\mathrm{A}$ and $\mathrm{B}$ immunolabeling was weaker (e.g., medial preoptic area, hippocampal formation, lateral septum); some areas had C-peptide immunolabeling equal to that of the other antisera (e.g., anterior olfactory nucleus, lateral nucleus of the amygdala); and in some areas $\mathrm{C}$-peptide-immunolabeled elements were more sparse than those stained with the other dynorphin antisera (e.g., peripeduncular nucleus, arcuate nucleus, lateral and medial habenula). These results and the observation that all antisera generated similar staining patterns in the rat support the argument that differential processing of the prodynorphin precursor molecule accounts for the differential staining observed in the hamster brain.

\section{The C-peptide antiserum}

The porcine and human prodynorphin gene have been sequenced (Kakidani et al., '82; Horikawa et al., ' 83 ), and the mRNA distribution has been described (Morris et al., '86). The properties of several precursor products as well as their separate distributions in the brain have been studied in detail (Goldstein et al., '79; Kilpatrick et al., '82; Watson et al., '82a,b, '83; Weber and Barchas, '83; Fallon and Leslie, '86). In 1983 Yamamoto et al. reported the synthesis of leumorphin, the carboxy-terminal sequence of prodynorphin, which contains the sequence of Leu-enkephalin at its amino terminus. These investigators also demonstrated a dosedependent opiate effect for leumorphin. It was later demonstrated to be an endogenous opioid in cow pituitary (Nakao et al., '83a) and to have kappa receptor agonist properties (Suda et al., '83, '84a). Though originally isolated from porcine neurointermediate pituitary, leumorphin was later sequenced from human genomic DNA. This human opioid differed from the porcine at three of the 29 amino acid residues yet still exhibited potent opioid activity (Suda et al., ' 84 b, '85).

In 1985, a synthetic peptide corresponding to the C-terminal 15 amino acid residues of the bovine prodynorphin molecule was made and antisera were generated against this amino acid sequence (Evans et al., '85). It was assumed that since there were no obvious processing signals in the form of basic residues or glycosylation sequences in the leumorphin $_{15-29}$ C-terminus, this fragment would remain intact during processing and be an excellent nonopioid prodynorphin marker. The antiserum used in the present study was formed against the C-terminus sequence (leumorphin ${ }_{15-29}$ ) in rat (Watson, personal communication), a peptide which differs in sequence from the porcine, bovine, and human. In the studies reported here, human and porcine $\mathrm{C}$-terminus peptides had no blocking effect on staining with the antise- 
rum directed against the rat $\mathrm{C}$-peptide in the hamster brain, but rat $\mathrm{C}$-terminus peptide blocked this staining completely at low micromolar concentrations. The antiserum showed no cross-reactivity with any other prodynorphin, proenkephalin, or proopiomelanocortin product.

\section{Biological activity of leumorphin}

Several biological activities have been described for leumorphin, including inhibition of electrically stimulated contraction of guinea pig ileum preparation (Yamamoto et al., '83), analgesia after intracisternal administration in mice (Yamamoto et al., '83), and stimulation of prolactin secretion from rat pituitaries ('Tojo et al., '85). In the rat it has also been implicated in facilitation of lordosis and estrous cyclicity in females, stimulation of locomotor activity, stimulation of food intake in nonfasted animals, and emission of semen in anesthetized males (Imura et al., '85; Suda et al., '86; Sakuma and Akaishi, '87). Based on these chemical, biological, and behavioral studies, leumorphin should be treated as a unique opioid peptide with novel properties, apparently differing from those of dynorphin B [1-13].

We have reported the labeling of cells, fibers, and terminals in the medial preoptic area, bed nucleus of the stria terminalis, and medial nucleus of the amygdala, as well as in fibers and cells of the stria terminalis, using an antiserum to the C-terminus of the leumorphin molecule. These structures are linked in a pathway which facilitates male hamster sexual behavior (Winans et al., '82). To the present, opioids have been implicated primarily in the inhibition of sexual behavior, yet leumorphin-like immunoreactivity is clearly concentrated in this excitatory pathway in the hamster. These findings, in conjunction with recent studies demonstrating facilitation of sexual reflexes and behavior by leumorphin, dynorphin $\mathrm{A}$, and dynorphin $\mathrm{B}$ in the male rat (Imura et al., '85; Sakuma and Akaishi, '87; Band and Hull, '88; Mitchell and Stewart, '88), suggest that leumorphin may have some functions which are distinctly different from those of other opioid peptides. Still to be answered are important questions about specific connections of these prodynorphin cell groups and the possible role of leumorphin as a neurotransmitter modulating sexual behavior in the Syrian hamster.

\section{ACKNOWLEDGMENTS}

We wish to thank Drs. Stanley J. Watson, Jr., and Lars Terenius for generously providing us with antisera for this study. Dr. Watson's advice and support throughout this study was greatly appreciated. We also thank Dr. Watson, Dr. Hylan Moises, and Dr. James Herman for critical reading of the manuscript. The morphology core of the Reproductive Endocrinology Program provided valuable technical assistance, supported by 1-P30-HD-18258. This work was supported by NIH grant NS20629 to S.W.N. and NIGMS grant GM10341 to C.R.N.J.

\section{LITERATURE CITED}

Adler, N.J. (1969) Effects of the male's copulatory behavior on successful pregnancy of the female rat. J. Comp. Physiol. Psychol. 69:613-622.

Akil, H., S.J. Watson, E. Young, M.E. Lewis, H. Khachaturian, and M.J. Walker (1984) Endogenous opioids: Biology and function. Annu. Rev. Neurosci. 7:223-255.

Allen, D.L., K.J. Renner, and V.N. Luine (1985) Naltrexone facilitation of sexual receptivity in the rat. Horm. Behav. 19:98-103.

Band, L., and E. Hull (1988) Opioids microinjected into central dopaminergic pathways: Effects on copulation in male rats. Soc. Neurosci. Abstr. 14:293.

Civelli, O., J. Douglass, A. Goldstein, and E. Herbert (1985) Sequence and expression of the rat prodynorphin gene. Proc. Natl. Acad. Sci. USA 82:4291-4295.

Dores, R.M., M.E. Lewis, H. Khachaturian, S.J. Watson, and H. Akil (1985) Analysis of opioid and non-opioid end products of prodynorphin in the substania nigra of the rat. Neuropeptides. 5-501-504.

Dornan, W.A., and C.W. Malsbury (1987) The effects of medial preoptic area injections of substance $P$ and cholecystokinin on male rat sexual behavior. Soc. Neurosci. Abstr. 13:613.

Dornan, W.A., C.W. Malsbury, and R.B. Penney (1987) Facilitation of lordosis by injection of substance $P$ into the midbrain central gray. Neuroendocrinology 45:498-506.

Evans, C.J., J.D. Barchas, F.S. Esch, P. Bohlen, and E. Weber (1985) Isolation and characterization of an endogenous C-terminal fragment of the $\alpha$-neoendorphin/dynorphin precursor from bovine caudate nucleus. J. Neurosci. 5:1803-1807.

Fallon, J.H., and F.M. Leslie (1986) Distribution of dynorphin and enkephalin peptides in the rat brain. J. Comp. Neurol. 249:293-336.

Gessa, G.L., and E. Paglietti (1979) Induction of copulatory behavior in sexually inactive rats by naloxone. Science $204: 203-205$.

Goldstein, A., S. Tachibana, L.I. Lowney, M. Hunkapillar, and L. Hood (1979) Dynorphin-(1-13), an extraordinarily potent opioid peptide. Proc. Natl. Acad. Sci. USA 76:6666-6670.

Haber, S.N., and W.J.H. Nauta (1983) Ramifications of the globus pallidus in the rat as indicated by patterns of immunohistochemistry. Neuroscience 9:245-260.

Horikawa, S., T. Takai, M. Toyosato, H. Takahashi, M. Noda, H. Kakidani, T. Kubo, T. Hirose, S. Inayama, H. Hayashida, T. Miyata, and S. Numa (1983) Isolation and structural organization of the human proenkephalin $B$ gene. Nature 306:611-614.

Imura, H., Y. Kato, Y. Nakai, K. Nakao, I. Tanaka, H. Jingami, T. Koh, Y. Yoshimasa, T. Tsukada, M. Suda, M. Sakamoto, N. Morii, H. Takahashi, K. Tojo, and A. Sugawara (1985) Endogenous opioids and related peptides: From molecular biology to clinical medicine. The Sir Henry Dale Lecture for 1985. J. Endocrinol. 107:147-157.

Kakidani, H., Y. Furutani, H. Takahashi, M. Noda, Y. Morimoto, T. Hirose, M. Asai, S. Inayama, S. Nakanishi, and S. Numa (1982) Cloning and sequence analysis of $\mathrm{cDNA}$ for porcine $\beta$-neoendorphin/dynorphin precursor. Nature 298:245-249.

Kevetter, G.A., and S.S. Winans (1981) Connections of the corticomedial amygdala in the golden hamster. I. Efferents of the "vomeronasal amygdala." J. Comp. Neurol. 197:81-98.

Khachaturian, H., S.J. Watson, M.E. Lewis, D. Coy, A. Goldstein, and H. Akil (1982) Dynorphin immunocytochemistry in the rat central nervous system. Peptides 3:941-954.

Khachaturian, H., M.E. Lewis, M.K-H. Schafer, and S.J. Watson (1985) Anatomy of the CNS opioid systems. Trends Neurosci. 8:111-119.

Kilpatrick, D.L., A. Wahlstrom, H.W. Lahm, R. Blacher, and S. Udenfriend (1982) Rimorphin, a unique, naturally occurring [leu]enkephalin-containing peptide found in association with dynorphin and $\alpha$-neoendorphin Proc. Natl. Acad. Sci. USA 79:6480-6483.

Lanier, D.L., D.Q. Estep, and D.A. Dewsbury (1975) Copulatory behavior of golden hamsters: Effects on pregnancy. Physiol. Behav. 15:209-212.

Lehman, M.N., S.S. Winans, and J.B. Powers (1980) Medial nucleus of the amygdala mediates chemosensory control of male hamster sexual behavior. Science 210:557-560.

Lehman, M.N., and S.S. Winans (1982) Vomeronasal and olfactory pathways to the amygdala controlling male hamster sexual behavior: Autoradiographic and behavioral analyses. Brain Res. 240:27-41.

Lehman, M.N., J.B. Powers, and S.S. Winans (1983) Stria terminalis lesions alter the temporal pattern of copulatory behavior in the male golden hamster. Behav. Brain Res. 8:109-128.

Lehman, M.N., and S.S. Winans (1983) Evidence for a ventral non-strial pathway from the amygdala to the bed nucleus of the stria terminalis in the male golden hamster. Brain Res. 268:139-146.

Lieblich, I., M.J. Baum, P. Diamond, N. Goldblum, C. Iser, and G. Pick (1985) Inhibition of mating by naloxone or morphine in recently castrated, but not intact male rats. Pharmacol. Biochem. Behav. 22:361364 .

Mansour, A., H. Khachaturian, M.E. Lewis, H. Akil, and S.J. Watson (1988) Anatomy of CNS opioid receptors. Trends Neurosci. 11:308-314.

Maragos, W.F., S.W. Newman, M.N. Lehman, and J.B. Powers (1989) Neurons of origin and fiber trajectory of amygdalofugal projections to the medial preoptic area in the golden hamster. J. Comp. Neurol. 280:59-71. 
McGinty, J.F., S.J. Henriksen, A. Goldstein, L. Terenius, and F.E. Bloom (1983) Dynorphin is contained within hippocampal mossy fibers: Immunochemical alterations after kainic acid administration and colchicineinduced neurotoxicity. Proc. Natl. Acad. Sci. USA 80:589-593.

McLean, S., R.B. Rothman, A.E. Jacobson, K.C. Rice, and M. Herkenham (1987) Distribution of opiate receptor subtypes and enkephalin and dynorphin immunoreactivity in the hippocampus of squirrel, guinea pig, rat and hamster. J. Comp. Neurol. 255:497-510.

McIntosh, T.K., M.L. Vallano, and R.J. Barfield (1980) Effects of morphine, $\beta$-endorphin and naloxone on catecholamine levels and sexual behavior in the male rat. Pharmacol. Biochem. Behav. 13:435-441.

Means, G.E., and R.E. Feeney (1971) Chemical Modification of Proteins. San Francisco: Holden-Day, p. 129.

Meyerson, B.J., and L. Terenius (1977) $\beta$-endorphin and male sexual behavior. Eur. J. Pharmacol. 42:191-192.

Meyerson, B.J. (1982) Neonatal $\beta$-endorphin and sexual behavior. Acta Physiol. Scand. 115:159-160.

Mitchell, J.B., and J. Stewart (1988) The effects of intra-VTA infusions of morphine and dynorphin (1-13) on male sexual behavior. Soc. Neurosci. Abstr. 14:849.

Morris, B.J., I. Haarmann, B. Kempter, V. Hollt, and A. Herz (1986) Localization of prodynorphin messenger RNA in rat brain by in situ hybridization using a synthetic oligonucleotide probe. Neurosci. Lett. 69:104-108.

Morrison, M., W. Steele, and D.J. Danner (1969) The reaction of benzoquinone with amines and proteins. Arch. Biochem. Biophys. 134:515-523.

Mumford, L., and R. Kumar (1979) Sexual behavior of morphine-dependent and abstinent male rats. Psychopharmacology 65:179-185.

Murphy, M.R., and G.E. Schnieder (1970) Olfactory bulb removal eliminates mating behavior in the male golden hamster. Science 167:302-304.

Murphy, M.R., D.L. Bowie, and C. Pert (1979) Copulation elevates plasma $\beta$-endorphin in the male hamster. Soc. Neurosei. Abstr. 5:470.

Murphy, M.R. (1981) Methadone reduces sexual performance and sexual motivation in the male golden hamster. Pharmacol. Biochem. Behav. I4.561-567.

Myers, B.M., and M.J. Baum (1979) Facilitation by opiate antagonists of sexual performance in the male rat. Pharmacol. Biochem. Behav. 10:615618 .

Myers, B.M., and M.J. Baum (1980) Facilitation of copulatory performance in male rats by naloxone: Effects of hypophysectomy, 17-estradiol and leutinizing hormone releasing hormone. Pharmacol. Biochem. Behav. 12:365-370.

Nakao, K., T. Yoshimasa, S. Oki, I. Tanaka, Y. Nakai, M. Wakimasu, M. Fujino, and H. Imura (1981) Presence of dynorphin-like immunoreactivity in rat pituitary gland and hypothalamus. Regul. Pept. 2:201-208.

Nakao, K., M. Suda, M. Sakamoto, T. Yoshimasa, N. Morii, Y. Ikeda, C. Yanaihara, N. Yanaihara, S. Numa, and H. Imura (1983a) Leumorphin is a novel endogenous opioid peptide derived from proenkephalin B. Biochem. Biophys. Res, Commun. 117:695-701.

Nakao, K., T. Yoshimasa, M. Suda, M. Sakamoto, Y. Ikeda, K. Hayash, and H. Imura (1983b) Rimorphin (dynorphin B) exists together with $\alpha$-neoendorphin and dynorphin (dynorphin A) in human hypothalamus. Biochem. Biophys. Res, Commun. 113:30-34.

Neal, C.R., S.W. Newman, and J.M. Swann (1989) The co-localization of substance $\mathbf{P}$ and prodynorphin immunoreactivity in neurons of the medial preoptic area, bed nucleus of the stria terminalis and medial nucleus of the amygdala of the Syrian hamster. Brain Res. (in press).

Newman, R., and S.S. Winans (1980a) An experimental study of the ventral striatum of the golden hamster. I. Neuronal connections of the nucleus accumbens. J. Comp. Neurol. 191:167-192.

Newman, R., and S.S. Winans (1980b) An experimental study of the ventral striatum of the golden hamster. II. Neuronal connections of the olfactory tubercle. J. Comp. Neurol. 191:193-212.

Palkovits, M., M.J. Brownstein, and N. Zamir (1983) Immunoreactive dynorphin and $\alpha$-neoendorphin in rat hypothalamo-neurohypophyseal system. Brain Res. 278:258-261.

Pearse, A.G.E., and J.M. Polak (1974) Bifunctional reagents as vapour- and liquid-phase fixatives for immunocytochemistry. Proc. R. Microsc. Soc. 9.67.

Pearse, A.G.E., and J.M. Polak (1975) Bifunctional reagents as vapour-and liquid-phase fixatives for immunocytochemistry. Histochem. J. 7:179186.

Pellegrini-Quarantotti, B., M.G. Corda, E. Paglietti, G. Biggio, and G.L. Gessa (1978) Inhibition of copulatory behavior in male rats by $\mathrm{D}$-ala ${ }^{2}$ met-enkephalinamide. Life Sci. 23.673-678.
Pfaus, J.G., and B.B. Gorzalka (1987) Opioids and sexual behavior. Neurosci. Biobehav. Rev. 11:1-34.

Platt, J.L., and A.F. Michael (1983) Retardation of fading and enhancement of intensity of immunofluorescence by p-phenylenediamine. J. Histochem. Cytochem. 31:840-842.

Powers, J.B., S.W. Newman, and M.L. Bergondy (1987) MPOA and BNST lesions in male Syrian hamsters: Differential effects on copulation and chemoinvestigatory behaviors. Behav. Brain Res. 23:181-195.

Sakuma, Y., and T. Akaishi (1987) Leumorphin, a novel opioid peptide, promotes lordosis in female rats. Brain Res. 407:401-404.

Seizinger, B.R., C. Grimm, V. Hollt, and A. Herz (1984a) Evidence for a selective processing of proenkephalin $B$ into different opioid peptide forms in particular regions of rat brain and pituitary. J. Neurochem. 42:447-457.

Seizinger, B.R., V. Hollt, and A. Herz (1984b) Proenkephalin B (prodynorphin)-derived opioid peptides: Evidence for a differential processing in lobes of the pituitary. Endocrinology 115:662-671.

Simerly, R.B., and L.W. Swanson (1986) The organization of neural inputs to the medial preoptic nucleus of the rat. J. Comp. Neurol. 246:312-342.

Smialowska, M., W. Lason, A. Bal, and R. Przewlocki (1985) Distribution of immunoreactive $\alpha$-neoendorphin in the rat brain. Neurosci. Lett. 62:359364 .

Sternberger, L.A., P.H. Hardy, J.J. Cuculis, and H.G. Meyer (1970) The unlabeled antibody enzyme method of immunohistochemistry. J. Histochem. Cytochem. 18:315-333.

Suda, M., K. Nakao, T. Yoshimasa, Y. Ikeda, M. Sakamoto, N. Yanaihara, S. Numa, and H. Imura (1983) A novel opioid peptide, leumorphin, acts as an antagonist at the kappa opiate receptor. Life Sci. 32:2769-2775.

Suda, M., K. Nakao, T. Yoshimasa, M. Sakamoto, N. Morii, Y. Ikeda, C. Yanaihara, N. Yanaihara, S. Numa, and H. Imura (1984a) Human leumorphin is a potent kappa opioid receptor agonist. Neurosci. Lett. 50:4952.

Suda, M., K. Nakao, M. Sakamoto, T. Yoshimasa, N. Morii, N. Yanaihara, S. Numa, and H. Imura (1984b) Leumorphin is a novel endogenous opioid peptide in man. Biochem. Biophys. Res. Commun. 123:148-155.

Suda, M., K. Nakao, M. Sakamoto, T. Yoshimasa, N. Morii, N. Yanaihara, S. Numa, and H. Imura (1985) Leumorphin in human brain. Neuropeptides 5:461-464

Suda, M., K. Nakao, M. Sakamoto, N. Morii, A. Sugawara, and H. Imura (1986) Changes in the immunoreactivities of an opioid peptide leumorphin in the hypothalamus and anterior pituitary during the estrous cycle of the rat and their relation to sexual behavior. Brain Res. 374:236-243.

Tojo, K., Y. Kato, H. Ohta, N. Matsushita, A. Shimatsu, Y. Kabayama, T. Inoue, N. Yanaihara, and H. Imura (1985) Stimulation by leumorphin of prolactin secretion from the pituitary in rats. Endocrinology 117:11691174.

Tokunaga, Y., T. Muraki, and E. Hosoya (1977) Effects of repeated morphine administration on copulation and on the hypothalamic-pituitary-gonadal axis of male rats. Jpn. J. Pharmacol. 27:65-70.

Watson, S.J., H. Khachaturian, D. Coy, L. Taylor, and H. Akil (1982a) Dynorphin is located throughout the CNS and is often co-localized with $\alpha$ neoendorphin. Life Sci. 31:1773-1776.

Watson, S.J., H. Khachaturian, H. Akil, D. Coy, and A. Goldstein (1982b) Comparison of the distribution of dynorphin systems and enkephalin systems in brain. Science 218:1134-1136.

Watson, S.J., H. Khachaturian, L. Taylor, W. Fischli, A. Goldstein, and H. Akil (1983) Prodynorphin peptides are found in the same neurons throughout rat brain: Immunocytochemical study. Proc. Natl. Acad. Sci. USA 80:891-894.

Weber, E., and J.D. Barchas (1983) Immunohistochemical distribution of dynorphin B in rat brain: Relation to dynorphin $\mathrm{A}$ and $\alpha$-neoendorphin systems. Proc. Natl. Acad. Sci. USA 80:1125-1129.

Winans, S.S., M.N. Lehman, and J.B. Powers (1982) Vomeronasal and olfactory CNS pathways which control male hamster mating behavior. In W. Breipohl (ed): Olfaction and Endocrine Regulation. London: IRL Press. pp. 23-34.

Wu, F.M.F., and R.G. Noble (1986) Opiate antagonists and copulatory behavior of male hamsters. Physiol. Behav. 38:817-825.

Yamamoto, Y., C. Yanaihara, Y. Katsumaru, T. Mochizuki, A. Tobe, M. Egawa, H. Imura, S. Numa, and N. Yanaihara (1983) Synthesis of porcine leumorphin and some of its biological activities. Regul. Pept. 6:163-168.

Zamir, N., M. Palkovits, and M.J. Brownstein (1983) Distribution of immunoreactive dynorphin in the central nervous system of the rat. Brain Res. 280:81-93. 